\title{
Lapurdum
}

Euskal ikerketen aldizkaria | Revue d'études basques |

Revista de estudios vascos | Basque studies review

$4 \mid 1999$

Numéro IV

\section{Affinités toponymiques cantabropyrénéennes et énigmes historiques}

\section{Hector Iglesias}

\section{OpenEdition \\ Journals}

Édition électronique

URL : http://journals.openedition.org/lapurdum/1557

DOI : 10.4000/lapurdum.1557

ISSN : 1965-0655

\section{Éditeur}

IKER

Édition imprimée

Date de publication : 1 octobre 1999

Pagination : $123-166$

ISBN : 2-84127-156-0

ISSN : 1273-3830

Référence électronique

Hector Iglesias, «Affinités toponymiques cantabropyrénéennes et énigmes historiques », Lapurdum [En ligne], 4 | 1999, mis en ligne le 01 juin 2010, consulté le 30 janvier 2020. URL : http:// journals.openedition.org/lapurdum/1557 ; DOI : 10.4000/lapurdum.1557 


\section{AFFINITÉS TOPONYMIQUES CANTABRO- PYRÉNÉENNES ET ÉNIGMES HISTORIQUES}

Cet article constitue la suite d'un autre intitulé "Sur quelques similitudes toponymiques galaïco-basques et le problème que posent certaines d'entre elles". La région traitée par notre étude s'avérera le plus large possible, englobant ainsi, outre dans quelques cas le Sud de l'Espagne, tout le Nord-Ouest de la péninsule ibérique depuis le nord de l'actuel Portugal jusqu'au Béarn puisque c'est un fait admis de tous les spécialistes en toponomastique que le facteur distance n'est pas un argument suffisant au moment de nier la parenté de plusieurs toponymes.

Il est vrai que dans la péninsule ibérique, malgré des décennies de recherches et les travaux d'illustres chercheurs tels que Joan Coromines, pour ne citer que lui, beaucoup de questions n'ont toujours pas été éclaircies de façon définitive. Dans le cas du Nord-Ouest de la péninsule les faits semblent parfois tout aussi ardus, voire la plupart du temps énigmatiques. Aussi le territoire étudié ici englobera essentiellement, entre autres, non seulement l'ancienne Asturia et Callaecia dont l'existence se reflète dans les titres des légats impériaux (Legati Augusti iuridici Asturiae et Callaeciae) mais également la Cantabria de l'Antiquité (c'est-àdire grosso modo l'actuelle région de Santander), le Pays Basque dans son ensemble, c'est-à-dire l'ibérique et le continental, ainsi que l'Aquitania de Jules César.

\section{1) La Galice : une abondance surprenante de toponymes}

Parmi toutes ces régions ibériques, la Galice semble présenter un intérêt particulier du point de vue des études toponymiques et cela pour une raison fort simple quoique la plupart du temps ignorée, même du public cultivé. Comme nous avons déjà eu la possibilité de le signaler succinctement au cours d'un article précédent, on trouve en Galice la bagatelle de 35000 toponymes majeurs, c'està-dire noms de villes, de "pays", de "communes" (c'est-à-dire en Galice des concellos, "conseils municipaux"), de villages, de hameaux, de paroisses (on en compte plus de 6000 et chacune d'entre elles célèbre sa fête au cours de l'été) et de vallées auxquels il faut ajouter des milliers de noms de montagnes et de cours d'eau qui, eux, ne constituent pas des toponymes majeurs à proprement parler. Ainsi, la toponymie majeure de ce pays est plus abondante que celle de tout le reste de l'État espagnol réuni, ce qui constitue une réalité méconnue. Au cours des Jornadas de Onomástica organisées à Vitoria-Gasteiz en 1986 par l'Académie de la Langue Basque, l'intervenant galicien, Antón Santamarina², ajouta même que si l'on devait comptabiliser tous les toponymes apparaissant dans les plans cadastraux, on atteindrait le nombre astronomique d'un million et demi de toponymes, certains d'entre eux apparaissant souvent, cela va sans dire, à plusieurs reprises. 
Le lecteur, amateur ou spécialiste, pourrait croire à une fantaisie. Il n'en est pourtant rien. La Galice est, on l'a dit, un pays méconnu et, en ce qui concerne l'Antiquité, mal connu. Délaissée par la propagande franquiste qui avait choisi d'ériger l'Andalousie en emblème de l'Espagne et décidé de faire de l'Andalou l'archétype de l'"Espagnol moyen", occultée par les situations basque et catalane, la Galice fut, à son insu, la grande oubliée de l'"hispanité". Isolée géographiquement, peu accessible encore récemment, dotée de peu d'infrastructures routières, rurale à l'extrême, ultra-conservatrice, archaïsante et peu hispanophone à tel point que le franquisme préférera ne pas interdire les publications locales en langue galicienne face à la méconnaissance quasi généralisée de la langue espagnole $^{3}$-, la Galice était et est encore pourtant un pays extrêmement singulier ${ }^{4}$ à plusieurs titres dont celui, évidemment, concernant la toponymie.

Ainsi, la singularité du fait toponymique galicien est telle qu'aussitôt une question vient à l'esprit : comment un pays comme la Galice qui compte à peine un peu plus de $29000 \mathrm{~km}^{2}$ (l'équivalent de l'État belge) peut-il à lui seul contenir plus de toponymes majeurs que l'ensemble de l'État espagnol dont la superficie est pourtant d'environ $500000 \mathrm{~km}^{2}$ ? Pour répondre à cette question, il faut remonter, d'après certains spécialistes, jusqu'à l'Antiquité.

\section{2) Les Callaeci de l'Antiquité et la Callaecia romaine}

Dès que l'on aborde pour le Nord-Ouest de la péninsule la période de l'Antiquité, les faits ont tendance à prendre une tournure pour le moins complexe. Comme le souligne Antonio de la Peña Santos ${ }^{5}$, c'est un fait que toutes les histoires nationales et les opinions patriotiques sont basées sur des mythes. Face au mythe euskarien privilégiant un ethnocentrisme basé sur l'isolationnisme (et ses dérivés folkloriques que sont la théorie "basco-paléolithique", le matriarcalisme et l'animisme) qui se développa fortement en Pays Basque au cours d'une époque encore récente, la Galice développa également le sien : celui du "celticisme". Ce mythe connut un tel succès que des secteurs très divers de la société galicienne, parfois radicalement opposés, en firent leur principal cheval de bataille au cours des deux derniers siècles.

Aujourd'hui, la ferveur "celtisante" des historiens et des poètes galiciens du XIX siècle s'étant quelque peu apaisée, les spécialistes pensent désormais que les populations celtiques, non seulement étaient minoritaires en Galice à l'arrivée des Romains mais de surcroît que leur influence sur la région n'aurait été en définitive que très limitée : elles n'auraient constitué qu'une petite oligarchie militaire et il semblerait même, souligne Ramón Mariño $\mathrm{Paz}^{6}$, qu'à l'arrivée de Rome leur langue fût déjà en voie d'extinction. D'après Johannes Hubschmid', à l'époque de la romanisation, le celte était peu présent en Hispania ou du moins fortement imprégné d'éléments pré-indo-européens et il est même possible que les langues pré-indo-européennes fussent tout à fait majoritaires. Alain Tranoy souligne, quant à lui, que le peuplement de la Galice dut se faire à partir d'un important fonds de peuplement préceltique. Pour certains auteurs, ajoute-t-il, "les Callaeci seraient même restés en dehors de ces vagues indo-européennes et représenteraient un peuple de la fin de l'âge du Bronze, en pleine expansion"".

\section{3) L'Ouesi et le Nord-Ouest de l'Hispanie : raccourci historique}

Alors qu'il avait fallu moins d'une dizaine d'années à Rome pour conquérir définitivement l'ensemble de la Gaule, la conquête de l'Hispanie ${ }^{9}$ s'étendit sur 
deux longs siècles et ne prit fin que lors du dernier soulèvement des Asturiens sous le règne de Claude et de Néron. Itaque ergo prima Romamis inita provinciarum quae quidem continentis sunt postrema omnium nostra demum aetate ductu auspicioque Augusti Caesaris perdomita est, écrit Tite-Live (XXVIII, 12) : autrement dit, l'Espagne, l'une des premières régions conquises, fut aussi l'une des dernières à être soumises. En 197 av. J.-C., Rome avait décidé de créer deux provinces : l'Hispania Ulterior et l'Hispania Citerior qui ne recouvraient, un demisiècle après sa création, qu'une moitié du territoire ibérique. Les Lusitaniens furent les premiers à attaquer d'emblée les troupes romaines et à ravager l'Hispania Ulterior. Dès l'arrivée des Romains, au début du Ile siècle av. J-C., les guerres entre les Lusitaniens et les Romains furent en effet permanentes. Diodore de Silice dit que les Lusitani (ancêtres grosso modo des Portugais) étaient un peuple ibère et non celtibère ${ }^{10}$, mais leur origine n'a pas pu encore être déterminée avec exactitude.

En 147 av. J.-C., Viriathe ou Viriatus", le plus célèbre des Lusitaniens et le plus puissant des chefs indigènes que connut la péninsule durant l'Antiquité ("le brigand Viriathe" écrit Strabon, Géogr., III, 4, 5), déclencha une offensive générale contre Rome et après sept ans de guerre totale, le gouverneur de l'Hispania Ulterior fut encerclé et dut négocier avec lui l'indépendance de la Lusitanie. A Rome, le Sénat, stupéfait, désigna alors le proconsul Q. Servilius Caepio, le frère du vaincu, afin de mener la contre-offensive. C'est ainsi qu'en 139 av. J.-C., il est fait mention pour la première fois des Galiciens. Appien (Iberica, 70) raconte qu'à cette époque $Q$. Servilius Caepio fit une simple incursion chez les Vettones et les Callaeci (la forme Gallaeci utilisée dans la Chronique d'Hydace ${ }^{12}$ semble plus tardive). C'est la première apparition de ce peuple dans l'Histoire. Un an ou deux ans plus tard, alors que les Romains luttaient toujours contre les Lusitaniens qui ne cessaient de pratiquer la guérilla avec l'aide de leurs femmes (chez les Lusitaniens et les Galiciens, les femmes et les hommes luttaient côte à côte d'après les auteurs anciens), ces derniers reçurent: l'aide d'un peuple habitant au nord des rives du Douro et que les sources nomment de nouveau Callaeci, nom que l'on traduit d'ordinaire par Callaïques. Ce peuple habitait probablement l'actuelle région de Porto. Il fut réprimé par un général romain - consul en 138 av. J.-C. et chargé initialement de lutter contre les Lusitaniens qui, même après la mort de Viriathe, continuaient à pratiquer la guérilla et refusaient de se rendre; près de 50 ans après la mort de leur célèbre chef, ils n'étaient toujours pas soumis et en 105 av. J.-C. ils avaient même remporté une autre victoire sur l'armée romaine - appelé Decimus Iunius Brutus qui, à, cause de la difficulté de cette guerre, reçut le surnom de Callaecus, au même titre que Scipion avait reçu celui d'Africanus après avoir vaincu les Carthaginois au cours de la bataille de Zama, en Afrique. Strabon (Géogr., III, 3, 2) l'indique : "Ces derniers [les Callaïques], à cause de leur âpreté au combat, qui est extrême, ont valu au Romain [Brutus] qui les a vaincus par les armes son surnom [Callaecus]".

C'est à cette époque que les Romains donnèrent à l'ensemble des peuples habitant la région qui va du Douro jusqu'au littoral océanique situé au nord de l'actuelle Galice, un territoire qui devait leur être presque totalement inconnu, le nom du peuple auquel ils s'étaient affrontés : les Callaeci furent donc ce qu'on nomme d'ordinaire un peuple éponyme, c'est-à-dire que leur nom devient celui de toutes les populations d'une région et peu importe qu'ill se fût agi de populi différents - ce qui était réellement le cas - ou non. Le fait devait être courant: 
puisque lorsqu'il cite les peuples aquitains, Pline l'Ancien mentionne le nom d'un petit peuple (les Aquitani) qui était selon lui à l'origine du nom de la province appelée Aquitania. Il écrit en effet (Nat. Hist., IV, 33) : Aquitani, unde nomen provinciae. Si on en croit ses dires, ces Aquitani auraient donc également joué, à l'instar des Callaeci, le rôle de peuple éponyme ${ }^{13}$.

\section{4) Les raisons de l'abondance extrême de toponymes en Galice'}

L'abondance de toponymes majeurs en Galice s'expliquerait alors ainsi : lorsque, après la conquête, le pouvoir romain commença à administrer les populations galaïques qui étaient sous son autorité, les fonctionnaires de Rome se seraient trouvés face à une organisation socio-politique indigène insolite et unique non seulement dans la péninsule ibérique mais également, semble-t-il, dans l'ensemble de l'empire romain. Cette organisation politique pourrait se résumer grosso modo ainsi : les divers populi que les Romains nommèrent indifféremment Callaïques formaient une sorte de "fédération" de peuples (une centuria) et chacun de ces peuples composant une centuria, constituait lui mêrne une "fédération" d'unités plus petite (des castella). Alain Tranoy signale que "la centuria correspond à un contenu de caractère social et ethnique et le castellum a essentiellement une fonction géographique et sociale"14. Lorsqu'un Galicien déclinait son origo, celui-ci faisait savoir à son interlocuteur qu'il possédait en réalité deux nationalités distinctes et ayant chacune un rôle important bien déterminé. Ce sont, d'après les spécialistes, plusieurs inscriptions de nature épigraphique qui le laisseraient supposer, par exemple : "pour Caelo, fils de Cadrolioco, appartenant au peuple des Cileni et ressortissant du castellum de Berisamus"'s.

Cette organisation indigène, de par son contenu politique et territorial incompatible avec le système romain basé sur les civitas, organisation socio-politique propre à l'empire, sera vouée à disparaître au fur à mesure qu'avancera la romanisation. Officiellement cette organisation disparaît, mais en fait cette ancienne réalité socio-politique continuera à exister de façon souterraine. Contrairement à ce qu'on aurait pu attendre, en Callaecia il n'y aura donc pas de véritables centres urbains, à l'exception de Lugo et de Braga qui sont des créations romaines. La population continuera alors à être disséminée sur tout le territoire, les fonctions municipales en général ayant alors lieu dans un lieu névralgique appelé forum: on avait ainsi, entre autres, le forum Narbasorum qui était le lieu où se réunissaient "ceux qui appartenaient au peuple galaïque des Narbasi ou Narbasons", cf. gr. Фópo̧ N $\alpha \rho \beta \alpha \sigma \widetilde{\omega v}$ (Ptol., II, 6, 48) ou bien le forum Iriensium, c'est-à-dire le forum de ceux de la localité d'iria (moderne Padrón, La Corogne), etc.; ces derniers, on l'a vu, constituant eux-mêmes une "fédération" d'unités plus petites. Cela expliquerait pourquoi on trouve aujourd'hui plus de noms de lieux en Galice que dans tout le reste de l'État espagnol réuni, du moins si on en croit certains spécialistes dont Gerardo Pereira-Menaut ${ }^{16}$.

\section{5) L'étymologie du nom Callaeci}

Déjà à la fin du siècle dernier, Emile Hübner doutait que ce nom puisse avoir une quelconque parenté avec celui des Galates, peuple d'Asie Mineure. Il faut en effet d'emblée distinguer le nom étudié ici de plusieurs autres qui lui ressemblent :

1. Une région d'Ukraine et de Pologne est appelée Galicie, en latin médiéval Galicia, Regnum Galiciae, en polonais Galicja, en russe Galitsia, en ukrainien Galicina et en allemand Galizien. Ce nom n'aurait, malgré les apparences, aucun 
rapport avec celui de la Galice ibérique. Il serait issu du vieux russe Galič, en polonais Halicz. Il s'agirait du nom d'une ancienne ville détruite en 1241 par les Mongols ${ }^{17}$.

2. Une ancienne province de l'Asie Mineure était connue sous le nom de Galatia. Elle était située dans l'actuelle Turquie, non loin de l'antique Cappadocia et de l'Arménie. C'était le pays des Galatae, nom qui serait en rapport avec celui des Galli, terme que les Romains utilisaient pour désigner tous les Celtes, à l'exception de ceux d'Asie Mineure. Les Celtes (on ne sait pas quel était le nom qu'ils se donnaient à eux-mêmes) furent d'abord appelés par les Grecs Keltoi, nom d'étymologie obscure, puis Galatai, ce vocable étant synonyme pour ces mêmes Grecs du premier, terme qu'on a voulu identifier, malgré les réticentes d'Emile Hübner ${ }^{18}$, à celui des Callaïques. De nos jours, cette hypothèse semble désormais abandonnée suite aux recherches les plus récentes, donnant ainsi raison à Hübner. En 1936, J. William Entwistle écrivait déjà : "Los galaicos, sin embargo (lat. GALLAECI, gr. Kaliaikoi), no eran, probabiemente, celtas, a pesar de la tentación de relacionar su nombre con el de los Galati o galos"'19.

3. La Gaule, en latin Gallia, c'est-à-dire les diverses régions peuplées par les Galli (Gaulois). D'aprẻs l'hypothèse la plus récente ${ }^{20}$, le nom Galli signifierait "les furieux" et se rattacherait au vieil irlandais gal, "vapeur, fureur". Les Grecs, on l'a dit, les appelaient Keltoi.

4. De nos jours, la majorité des auteurs semblent s'accorder pour voir dans le nom du peuple éponyme Callaeci, d'où est issu le nom du pays Callaecia $>$ Gallaecia > Galicia, un nom pré-indo-européen. Le nom des Callaici / Callaeci, en grec Kallaikoi s'analyse d'ordinaire ainsi : Call-aici, -us / Kall-aiko-, avec suff. *-aiko-. Ce suffixe indigène du Nord-Ouest hispanique avait pour fonction de transformer des noms de lieux (propres ou communs) en formes adjectivales, c'est-à-dire qu'il avait grosso modo la même valeur que le suffixe latin -ensi--, Le nom de peuple Kallaikoi serait un dérivé du terme pré-indo-européen *kalla-, sa signification étant alors *kallaiko-, "montagnard, habitant des hauteurs, des montagnes". Cette étyrnologie semble d'ailleurs confortée par les propres dires de Strabon (Géogr, III, 3, 2), lorsqu'il cite "les Callaïques ${ }^{21}$, qui occupent une grande partie de la région montagneuse”.

5. Alain Tranoy signale, en effet, qu'en "remontant du Tage vers le nord, Brutus eut, après avoir franchi le Douro, de nombreux combats à mener"22 d'aprés Appien. De sorte que l'extension du nom des Callaeci à tous les peuples vivant au nord du Douro dut se faire à partir du nom du premier peuple que Brutus rencontra en remontant vers le nord, ce qui s'avère être en effet l'hypothèse la plus économique, donc la plus probable. En outre, il a été trouvé à une vingtaine de kilomètres de Porto, une dédicace à une divinité locale où l'on peut lire : CALAICIA[E] / RVFVS FL/AVI F(ilius) / S(acrum) F(aciendum) C(uravit). Cette divinité CALAICIA pourrait peut-être, d'après Alain Tranoy ${ }^{23}$, constituer un indice attestant l'établissement des Callaeci dans la région de Cale, c'est-à-dire de l'actuel Porto, l'étymologie la plus courante de ce nom antique étant: Cale < *kallai, "les hauteurs, les collines", avec un nominatif pluriel pré-latin en -ai selon J. Untermann ${ }^{24}$. Ce toponyme correspondrait en outre pleinement aux caractéristiques géographiques du lieu de Porto. Il faut signaler la similitude de *kallai et du nom de peuple *kallaiko- avec le terme basque actuel garai, "haut, hauteur" avec sonorisation courante en basque de l'occlusive initiale. En outre, Luis 
Michelena signale que garai semble correspondre exactement au terme "galaique l'on trouve dans le mot espagnol galayo, "prominencia de roca pelada que se eleva en un monte" 25 .

\section{6) Les traditions indigènes et leurs répercussions sur les Études Basques}

6. En ce qui concerne tous les aspects, entre autres, ethnographiques concernant les peuples du Nord-Ouest de la péninsule ibérique pendant l'Antiquité, le lecteur intéressé par cette question pourra consulter l'ouvrage d'Alain Tranoy, considéré comme un ouvrage de référence. De plus, cet aspect concerne indirectement le Pays Basque ou tout au moins les Vascones que l'on considère d'ordinaire comme étant les ancêtres de la plupart des Basques actuels. Les détails que nous livrent les auteurs anciens sur les mœurs de ces populations de Lusitanie et de Galice sont très intéressants. La participation active des femmes lusitaniennes et galaïques aux diverses guerres contre Rome est attestée par plusieurs auteurs antiques. Mais le plus étonnant est le témoignage qui suit : un auteur tardif, le patriarche Photius, se fondant sur les écrits, aujourd'hui disparus et intitulés l'es choses incroyables que l'on voit au-delà de Thule, à savoir au-delà des limites du monde connu des Anciens, un ouvrage composé par un auteur gre:c du ${ }^{e r}$ siècle ap. J.-C., Antonius Diogène, raconte que chez les Artabres, un peuple galaïque qui habitait dans l'actuelle province de La Corogne, les femmes faisaient la guerre pendant que les hommes restaient à la maison. Julio Caro Baroja ${ }^{26}$ rappelle que les récits de Diogène servirent de base à un écrivain français du XVIII ${ }^{e}$ siècle, Mathieu de Chiniac de la Bastide, au moment d'écrire une Dissertation sur les Basques (Paris, 1786).

7. Pour le reste, chez les Galiciens, les hommes avaient pour habitude de ne rien faire, sinon de se consacrer principalement, en dchors de la guerre, aux rapines et aux brigandages de toutes sortes, tandis que tous les travaux agricoles étaient assurés uniquement par les femmes, du moins si on en croit les témoignages de Justin, de Silius Italicus et de Clément d'Alexandrie ${ }^{27}$. Les Lusitaniens et les Callaïques avaient également pour habitude de consulter le foie des victimes, de tenir compte du vol des oiseaux et des manifestations célestes telles que la foudre. Ils dansaient et chantaient en frappant le sol et en faisant résonner leur bouclier. Strabon nous dit aussi qu'ils jouaient de la musique avec des flûtes et des trompettes et qu'ils vénéraient la lune, fait que rapporte aussi Ptolémée ${ }^{28}$. Ce rite a effectivement survécu en Galice jusqu'au début du $\mathrm{XX}^{\circ}$ siècle : dans une région de la province d'Orense, les paysans avaient en effet pour coutume, signale Alain Tranoy ${ }^{29}$, de se réunir les nuits de pleine lune pour danser et chanter en l'honneur de cet astre.

8. C'est à présent qu'il faut mentionner un témoignage de Strabon qui intéresse les Basques de l'Antiquité et les Études Basques en général. Pour des raisons qui nous échappent, probablement suite à une interpretatio exagérée, un des plus importants témoignages de Strabon sur les mœurs des populations d'Ibérie (Strabon est du point de vue ethnographique celui qui donne les informations les plus intéressantes concernant les peuples de l'Antiquité) a été constamment et, manifestement, abusivement attribué aux Vascones de l'Antiquité. İl est en effet de nos jours devenu courant, parmi certains auteurs, principalement du Pays Basque, d'attribuer aux Vascones et aux seuls Vascones une série de coutumes rapportées par Strabon. Cependant, un retour aux sources montre clairement que le témoignage de Strabon (Géogr., III, 3, 7) n'est rien d'autre qu'une description 
des coutumes des Lusitaniens et des Galiciens de l'Antiquité - ces deux noms furent en effet synonymes, probablement de 19 à 7 ou peut-être 2 av. J.-C., étant donné qu'à cette époque la Galice et les Asturies furent incorporées par Auguste à la Lusitania". C'est Strabon (Géogr., III, 4, 20) qui nous l'indique : le "pays des Lusitaniens selon l'appellation ancienne, des Callaïques selon l'appellation moderne".

9. Il s'agit d'un témoignage précieux et par conséquent, il n'est pas inutile de rappeler les dires du géographe grec : "Les Lusitaniens font des sacrifices. Ils examinent les entrailles sans ectomie. Ils examinent aussi les vaisseaux du flanc et se livrent à la divination en les touchant. Ils procèdent aussi à des consultations d'entrailles humaines sur la personne de leurs prisonniers de guerre". En outre, "les montagnards [de Lusitanie, c'est-à-dire les Callaïques] sont tous sobres. Ils ne boivent que de l'eau et couchent à même le sol. Ils laissent descendre très bas leurs cheveux, comme des femmes, mais les relèvent sur le front par un bandeau pour le combat. Ils se nourrissent surtout de chair de bouc". Et il ajoute : "les populations montagnardes [de Lusitanie] vivent pendant les deux tiers de l'année de glands de chênes. On les sèche et les concasse, puis on les réduit en farine pour en faire ur pain qui se conserve longtemps. Ils boivent généralement de la bière, rarement du vin, et celui qu'ils ont est vite consommé dans les banquets familiaux. Ils remplacent l'huile par le beurre. Leurs festins se font assis : à chaque convive est réservé le long de la paroi un siège construit avec le mur, où l'on prend place selon son âge et son rang, puis les mets sont passés à la ronde. Quand on commence à boire, les hommes se mettent à danser, tantôt évoluant en chœurs au son de la flûte et de la trompette, tantôt aussi en sautant et en s'accroupissant alternativement [...]. Les hommes sont tous habillés de noir, le plus souvent d'une saie. Ils s'en enveloppent pour dormir sur leurs litières de feuilles et d'herbes sèches. Comme les Celtes [ce qui sous-entend que les Lusitaniens et les Callaïques ne l'étaient effectivement pas], ils usent de vases de cire".

Puis, il signale "qu'on précipite du haut des rochers les condamnés à mort. On lapide les parricides, mais loin des montagnes et des cours d'eau" et "les malades, comme c'était anciennement le cas chez les Égyptiens, sont exposés sur la voie publique". La confusion avec les Basques provient certainement du fait que Strabon conclut : "Tel est le genre de vie, comme je l'ai dit, des populations montagnardes [toujours de Lusitanie]". Après quoi, il ajoute que les autres populations qui jalonnent le côté nord de l'Ibérie “jusqu'au Pays des Vascons et au Mont Pyréné (sic)" vivent de la "même manière" "31.

\section{7) Hydronymes préceltiques cantabro-pyrénéens liés peut-être à la Sibérie}

Les noms de cours ou hydronymes constituent pour les spécialistes, qui semblent s'accorder au moins sur ce point, les couches les plus anciennes de la toponymie. Nos recherches sur ce sujet, à notre connaissance inédites sur bien des points et déjà exposées, en partie du moins, lors de notre dernier article ${ }^{32}$, semblent être en passe de donner des résultats intéressants, certains d'entre eux s'avérant même surprenants.

\section{1) Lena et Lea}

10. Nous avons en effet déjà eu l'occasion de signaler qu'une rivière biscaïenne s'appelle Lea (Lekeitio, Biscaye). Nous avions comparé ce nom avec celui d'un petit village galicien de Lugo connu sous le nom de Lea. D'autres recherches 
entreprises par la suite, et qu'à notre connaissance aucun autre auteur ne semble: avoir menées, nous permettent de dire qu'il existe en fait deux villages en Galice ayant ce nom (Lea et Riberas de Lea) et, surtout, que ces deux localités tiennent manifestement leur nom de la petite rivière qui les traverse tous les deux : la rivière galicienne appelée Lea, autrefois une des deux localités étant appelée par le même nom : Domnus Ciprianus, clericus de Lea, 1252 (cartulaire de Lorenzana). Ainsi, on constate que la Galice et la Biscaye ont chacune sur leur territoire respectif une rivière dù même nom. En outre, nous avíons comparé le toponyme Lea avec le nom d'une localité située dans la montagne asturienne : Pola de Lena située au sud de Mieres. Ce que nous ne savions pas à l'époque était que cette localité montagneuse des Asturies, que nous avons eu l'occasion de visiter par la suite, tire également son nom d'une petite rivière appelée rio Lena, d'où son nom : Pola de [la rivière] Lena, le mot asturien pola étant vraisemblablement, mais ce n'est pas sûr, l'équivalent du terme espagnol puebla. Or, en galicien et en basque, contrairement à ce qui se produit en asturien, les -n-intervocaliques s'effacent, ce qui nous avait permis de reconstruire pour l'hydronyme galaïco-biscaïen une proto-forme *lena que l'existence du cours d'eau asturien conforte assurément (au XVI ${ }^{e}$ siècle, la véritable forme asturienne était Llena étant donné que dans cette région l'asturien palatalise systématiquement les $l$-à l'initiale, le nom ayant été par la suite espagnolisé d'un point de vue phonétique ${ }^{33}$ : *lena > Llena $>$ Lena, en basque et en galicien l'évolution ayant été manifestement, quant à elle, *lena $>$ Lea). Il semblerait en effet qu'on puisse tenir pour acquis, ou tout au moins que cela semble extrêmement probable, que le Lea galicien, le Lea biscaïen et le Lena asturien ont la même origine.

1I. De surcroît, il s'agit dans les trois cas d'hydronymes, on les appellera hydronymes cantabro-pyrénéens, c'est-à-dire une catégorie de noms que les spécialistes considèrent comme représentant les couches les plus profondes de la toponymie, ce qui, de surcrôit, semble témoigner d'une certaine unicité ethnolinguistique de tout le Nord-Ouest de la péninsule ibérique à une époque indéterminée, unicité à laquelle Strabon, on l'a vu, semble également faire référence. A l'évidence, de telles similitudes ne peuvent être dues au simple hasard. En outre, ces hydronymes sont à ranger dans la catégorie des hydronymes préceltiques et très vraisemblablement pré-indo-européens.

12. Pour être tout à fait complet, il faut signaler que Joan Coromines avait au cours de ces études reconstruit une forme *lěna baptisée par lui pyrénéenne et à laquelle il attribuait le sens de "losa, dalle de pierre" ${ }^{34}$ (il citait le vocable du Pallars occidental llenat, "techo de pizarra"). Il est curieux qu'il n'ait pas remarqué que cette forme existait déjà en réalité dans les Asturies sous forme d'hydronyme. La preuve qu'il ne l'avait manifestement pas vue semble se trouver dans ses écrits : "el área de *lěna hacia el oeste no pasa de Aragón, que yo sepa" ". Il faut cependant avouer qu'il s'agit d'une petite rivière de montagne et d'un village asturiens peu connus.

13. En outre, il faut également signaler en ce qui concerne le Lea biscaïen, qu'Alfonso Irigoyen signalait pour ce norn une forme médiévale Leia ${ }^{36}$, ce qui ne change rien à notre démonstration puisqu'il est très courant en basque, et notamment en biscaïen, que des épenthèses d'i consonnes intervocaliques se produisent après d'autres voyelles pour détruire des hiatus. Henri Gavel ${ }^{37}$ signale qu'en souletin et biscaïen le mot espagnol leal est couramment prononcé leial. Ce phéno- 
mène est également très courant en galicien ${ }^{38}$ et aussi en basque commun. Par conséquent, la forme médiévale biscaïenne Leia constituait elle même très probablement une forme secondaire issue d'un plus ancien Lena (cf. Asturies) > Le(n)a > Leia (avec $i$ consonne détruisant le hiatus vocalique produit par l'effacement en basque de la nasale intervocalique) $>$ Lea (forme actuelle) $>$ Liai ou Liei (formes populaires biscaïennes selon Irigoyen ${ }^{39}$ ).

\section{2) L'ouralo-altaïque : une vieille hypothèse très controversée}

14. On ne peut à présent ne pas signaler un fait extrêmement curieux qui demanderait des recherches beaucoup plus approfondies : un grand fleuve de Sibérie, qui, après avoir arrosé les plateaux de Sibérie centrale, coule au pied de la grande chaîne de montagnes de Verkhoïansk qui culmine à 2959 m, porte le nom de Lena. On ne peut dans l'état actuel de nos recherches dire s'il s'agit uniquernent d'apparences trompeuses, qui existent mais que l'on ne doit en aucun cas exagérer, ou s'il s'agit d'une véritable piste toponymique qu'il faudra à l'avenir examiner sérieusement. Cependant, si les apparences trompeuses peuvent en effet exister comme le rappelle Jacques Ailières ${ }^{40}$, qui signale que l'anglais bad, "mauvais" et le persan bad, "id.", malgré les apparences, ont une origine radicalement différente, elles ne sont pas d'ordinaire aussi nombreuses qu'on pourrait le croire.

15. Outre le fait qu'il s'agit dans tous les cas (galicien, asturien, basque et sibérien) de noms de cours d'eau dont l'origine préceltique, dans le cas des hydronymes cantabro-pyrénéens, ne fait guère de doute, ce qui diminue considérablement le risque - mais, il est vrai, ne l'élimine pas totalement - d'une apparence illusoire, on rappellera au demeurant que Jacques Allières souligne que la famille ouralo-altaïque montre "une stabilité remarquable; c'est ce que l'on a noté dans le domaine altaïque - les dialectes turcs, du Bosphore à la Sibérie, sont peu différenciés - et peut-être du basque, précisément, langue qui s'est très peu modifiée depuis les premiers textes" $"$. II faudrait alors connaître la forme ancienne de cet hydronyme sibérien. On sait, toutefois, que ce nom est déjà attesté au début du XVII" siècle sous une forme manifestement identique à l'actuelle: "The delta was discovered in 1637 by the Cossack. Elisei Busa, who sailed down the Lena and through the western arm of the delta to the Olenek river where he wintered" $\$ 2$. Nous n'avons pas pu nous procurer de formes plus anciennes, mais il est vraisemblable que celles-ci devaient probablement être, pour les raisons évoquées cidessus, proches sinon identiques à l'actuelle. A notre connaissance, le seul auteur. qui essaie d'expliquer cet hydronyme sibérien est André Cherpillod dont les étymologies, néanmoins, ne sont pas toujours, comme il le reconnaît lui-même, très sûres eu égard à la difficulté qu'entraîne l'analyse de certains de ces noms de Sibérie orientale. Selon lui, ce nom pourrait être issu de l'évenki (langue altaïque du groupe toungouse) yelyuyon, "rivière" ${ }^{43}$. Il semblerait en effet acquis que ce toponyme ne soit pas un nom slave donné après lat conquête de ces contrées par les Russes. L'avenir nous dira si cette piste doit être approfondie ou non.

16. On ne pourrait guère, toutefois, invoquer l'invraisemblance d'une telle parenté toponymique présumée au nom de l'éloignement géographique et nier ainsi toute crédibilité à cette hypothèse cantabro-sibérienne puisque c'est un fait acquis aujourd'hui, tous les spécialistes s'accordent sur cette question, que plus on recule dans le passé plus le facteur distance doit être négligé, voire carrément écarté ${ }^{44}$. Il est loin d'être inconcevable de supposer qu'à ces époques reculées des populations sibériennes se soient dirigées vers la péninsule ibérique et l'aient: 
atteinte en quelques mois, voire tout au plus en quelques années puisque ces groupes de chasseurs-cueilleurs du Paléolithique pouvaient, comme s'accordent à le penser actuellement les plus imminents spécialistes de la préhistoire ${ }^{45}$, parcourir jusqu'à cinquante kilomètres par jour à la recherche de nourriture. Ces populations sibériennes se seraient alors établies et disséminées le long de la Cordillère Cantabrique depuis la Galice jusqu'à l'actuel Pays Basque, ce qui expliquerait la présence de noms de cours d'eau identiques dans ces régions et leur ressemblance tout à fait frappante avec l'hydronyme sibérien mentionné auparavant. Des reliquats de la langue de ces populations de Sibérie auraient pu se conserver dans la langue basque actuelle, qui reposerait alors sur un socle sibérien, puisque, on le sait, la ou plutôt les langues des Callaïques, des Astures et des Cantabres ont quant à elles disparu. Cela n'est certes pas acquis, mais la piste semble intéressante et mériterait probablement d'être approfondie. C'est au demeurant l'hypothèse défendue par Michel Morvan ${ }^{46}$, bien que sa thèse ne concerne pas à proprement parler la toponymie.

17. En guise de conclusion, nous dirons - bien que l'ouralo-altaïque n'entre pas dans le domaine de nos compétences - que cette hypothèse sibérienne ${ }^{47}$ reprise récemment de Michel Morvan ne paraît pas invraisemblable. Les réticences de certains chercheurs face aux travaux de cet auteur proviennent essentiellement du fait que se fonder sur des ressemblances lexicales actuelles, alors que l'on a affaire à des langues dépourvues de tradition écrite ancienne, apparaît encore à beaucoup de linguistes très discutable. En revanche, l'hydronymie fait appel à des formes fossilisées depuis, la plupart du temps, des millénaires, point sur lequel tout le monde s'accorde. Cela rend, à notre avis, plausible cette hypothèse concernant l'hydronyme sibérien Lena. Cependant, il faut reconnaître qu'à partir d'une seule équivalence toponymique, de surcroît hypothétique, toutes ces conjectures paraissent bien fragiles. En outre, il existe un autre fait qui semblerait fragiliser encore plus cette hypothèse cantabro-sibérienne : Gerhard Rohlfs ${ }^{48}$ rappelle qu'en Catalogne et en Aragon, voire en Gascogne et en Ariège, on rencontre plusieurs toponymes, notamment des oronymes, tels que Serra la Llena, Cova de les Llenes, Liena, Port de la Lleia, Lia, Lena, etc. pour lesqueis il reconstruit une base préromane, en se basant sur les travaux de Coromines et de Hubschmid qu'il cite, *lèna (cf. supra). Rohlfs signale également que ces vocables représentent "le fonds le plus important parmi les survivances préromanes. Il s'agit de mots limités aux vallées pyrénéennes [manifestement, lui non plus n'avait pas remarqué le Lena asturien] et dont on peut souvent démontrex l'existence dans les parlers des deux versants. Dans les cas où de tels mots sont communs au gascon, à l'aragonais et au catalan, il est permis de parler d'un véritable vocabulaire pyrénéen". Il précise également qu'il s'agit de "mots d'origine mystérieuse, qui semblent appartenir à un peuple disparu"49. Il faut, toutefois, noter qu'il ne s'agit jamais, sauf erreur de notre part, d'hydronymes. Or curieusement, en Galice, dans les Asturies, en Biscaye et en Sibérie, il s'agit dans tous les cas de noms de cours d.eau. Comment pourrait-on expliquer ce fait? Il se peut aussi qu'il n'y ait pas de rapport entre les oronymes et les hydronymes cités ci-dessus.

\section{3) Uncín et Untxin}

18. Nos recherches nous permettent également de signaler un fait qui, à notre connaissance et sauf erreur de notre part, n'avait pas été mentionné auparavant. Une petite rivière des Asturies occidentales traversant la localité d'Artedo, a pour 
nom Uncín. Il s'agit manifestement du même nom que celui de la rivière d'Urrugne appelée Untxin, autrefois Onzi, 1235 (Livre d'Or), Ouncin, $\mathrm{XIX}^{c}$ siècle $^{50}$. Une des explications envisageables, si l'on accepte cette similitude hydronymique basco-asturienne et si l'on veut l'interpréter, est de postuler un même peuplement ancien, c'est-à-dire que cette région asturienne et cette partie de la côte labourdine auraient été peuplées, à une époque indéterminée, par des groupes ethno-linguistiques apparentés. On pourrait peut-être rapprocher ce nom du terme basque untzi, "récipient" et également "cuvette", sens que Jean-Baptiste Orpustan considère "acceptable en toponymie mais des plus incertains"st. Michel Morvan compare le basque ontzi, "récipient creux" au finnois onsi, "creux"s2.

\section{8) Les hydronymes cantabro-pyrénéens Eo, Ego, Oo et les Egovarri de Pline}

19. On a ici probablement affaire à des appellations hydronymiques qui se perdent dans les couches les plus profondes de la toponymie. Ainsi, dans les montagnes luchonnaises, riches en lacs, un village et un lac sont appelés tous les deux Oo. L'appellation "le lac d'Oo" est probablement une construction tautologique, la forme $O o$ étant vraisemblablement issue, suite à une assimilation vocalique, d'un plus ancien *eo. Dans la vallée d'Ossau, le terme communément utilisé pour désigner les lacs de montagne de la région est ioû, éôे, héou, uôे. Gerhard Rohlfs consacre tout un passage à ces hydronymes pyrénéens pour lesquels il reconstruit une base *ibone $e^{53}$.

20. Or la proto-forme de cet hydronyme pyrénéen se serait conservée sous sa forme pleine, ce qui dénote une remarquable stabilité phonétique, dans le nom :le la rivière basque appelée Ego, autrefois val de Ego, $1335^{\text {s4 }}$, cours d'eau séparant les localités d'Ermua (Biscaye) et d'Eibar (Guipuscoa). Mais le cas le plus intéressant est sans nul doute celui concernant le fleuve galaïco-asturien appelé Eo. Ce fleuve sépare aujourd'hui d'un point de vue administratif la Galice des Asturies, bien qu'il fût situé autrefois à l'intérieur du territoire des Callaïques. P. Fouché a restitué pour ce nom galaïco-asturien une proto-forme hypothétique *eoo alors qu'en réalité, à notre avis, l'explication est beaucoup plus simple : en fait la proto-forme qui doit être restituée pour cet hydronyme galicien est assurément *ego. Ce qui complique un peu l'explication de ce nom est le fait que plusieurs erreurs se sont accumulées les unes sur les autres au cours du temps. Afin ne pas ajouter à la confusion, il faut tenter d'expliquer comment et où se sont produites ces méprises.

21. Les anciennes formes médiévales de ce nom de cours d'eau galicien sont : Yube, 775, Euve, Eube, 925, Euuio, 1128, et in Asturiis sicut dividit ripa Ove, 1157 , usque in flumen Ove, XII ${ }^{\circ}$ s., en ce qui concerne les sources de cette rivière, les formes archaïques étant ${ }^{55}$ : Fonte Euve, 1188, F. Eve, 1269, Fonteu, 1301. La première erreur qui s'est produite est en effet également la principale, celle qui détermine toute la suite des événements. Cela étant, cette erreur ne peut être déduite que d'un point de vue phonétique. En effet, il existe une certitude : à partir des formes médiévales citées ci-dessus on ne peut pas aboutir à la forme actuelle Eo. Cela implique, aussi curieux que cela puisse paraitre, que les scribes du moyen âge se sont trompés et non, comme nous l'écrivions dans notre dernier article, V. Olano Silva. Effectivernent, bien qu'ils écrivent in flumen Euve ou Ove, ce nom ne peut être que celui d'une paroisse galicienne appelée Obe située au sud de celle de Ribadeo et à côté de la rivière Eo. D'ailleurs, il existe un document médiéval qui fait expressément référence à cette paroisse connue de nos jours 
sous le nom d'Obe : in Santi Iohannis d'Eune, s. d. prob. XI-XII' s. (cartulaire de Lorenzana, ici il ne s'agit pas du fleuve). En outre, il existe également à côté de cette paroisse un hanneau de cinq maisons appelé Río de Obe, nom qui malgré les apparences ne désigne pas un cours d'eau (IGN, Ribadeo, feuille 10-III, 17-6). En effet, les formes médiévales citées ci-dessus impliquent toutes une proto-forme, comme le suppose également Abelardo Moralejo Lasso ${ }^{56}$, Egobe puisque l'évolution *Egobe $>$ Eube $>O v e>O b e$ serait alors tout à fait normale et régulière en phonétique galicienne. Autrement dit, ce que les scribes du moyen âge croyaient être le nom d'un cours d'eau était en réalité celui d'une localité située à côté de celui-ci.

22. Pline l'Ancien (Nat. Hist., IV, 111) mentionne parmi les Callä̈ques luquois ou Callaeci lucenses un peuple (et non pas une "ville" comme le dit, probablement par inadvertance, Humboldt) connu sous le nom d'Egovarri. Mais il existe un fait qui vient passablement compliquer cette question. En effet, il y a deux lectures du texte de Pline : celle que nous avons citée et une autre, utilisée par la plupart des auteurs au cours principalement du XX $\mathrm{XX}^{\mathrm{c}}$ siècle, entre autres, par Hübner, et qui semble manifestement erronée, c'est-à-dire Egivarri ou Egi, Varri ${ }^{3}$. Humboldt, qui utilise une édition de Pline du XVIII' siècle (il utilise les éditions du jésuite français Hardouin, $1^{\star}{ }^{\star}$ éd. $1685 ; 2^{\circ}$ éd. corrigée, Paris, 1723, $3^{\circ}$ éd. 1741) opte pour la forme, à notre avis correcte, Egovarri. Emile Littré, dans son édition parue en 1848 , fait de même. A partir de là, il existe quatre autres éditions, toutes allemandes : celle de Sillig (6 vol., Hambourg et Gotha, 1851-1855), celle de Jan (6 vol., Leipzig, 1854-1865), celle de Detlefsen (5 vol., Berlin, 1866-1873) et enfin celle de Carl Mayhoff ( 5 vol., Lei.pzig, 1892-1906). Ce sont dans ces deux dernières éditions que l'on lit actuellement P'line avec le plus de confiance ${ }^{j 8}$. La plupart des auteurs qui étudie le texte de Pline utilise en effet l'édition de Carl Mayhoff. Cependant, dans le cas de ce peuple galaïque qui relevait du conuentus de Lugo, Mayhoff ${ }^{\text {s9 }}$ s'est très probablement trompé puisque contrairement à Emile Littré et à Humboldt, il préfère lire Egivarri ou Egi, Varri (quoique dans ses notes, il cite également la forme egoua $-v[$ arri $]$ ).

23. Dans notre dernier article ${ }^{60}$, nous écrivions : "On peut affirmer que le nom Egovarri est à l'origine de l'hydronyme Eo pour une simple et unique raison : les actuels habitants des rives de ce fleuve aujourd'hui galaïco-asturien, c'est-à-dire principalement ceux des villages galiciens de Ribadeo et d'Obe et ceux des villages asturiens de Vegadeo et de Castropol, sont encore de nos jours désignés par le terme générique Egovarros". Nous nous basions pour cela sur l'ouvrage d'un auteuĩ asturien bien au fait des réalités locales : Xosé Lluis García Arias. Son ouvrage linguistique est considéré comme étant un travail de qualité, mais les vérifications que nous avons effectuées ultérieurement ne nous permettent pas de confirmer ses dires sur ce point. C'est qu'en réalité le texte de García Arias fait preuve à un moment donné d'une certaine ambiguïté. Celui-ci laisse en effet supposer, en employant peut-être abusivement le présent, que les gens de la région en question sont encore de nos jours désignés ainsi : "a los habitantes de sus riberas [de l'Eo] se les alude genéricamente como Egovarros" ${ }^{\prime \prime}$, écrit-il, ce qui pourtant ne paraît pas être le cas d'après les informations recueillies auprès du secrétariat général de la mairie de Ribadeo. En outre, nous ne savons pas si au cours du moyen âge la forme Egovarros était encore employée pour désigner ces populations. Nonobstant, et cela peut paraître paradoxal, que cet auteur asturien ait commis ou non une erreur n'invalide pas notre précédente démonstration. 
24. Les Egovarri de Pline habitaient bien la région de l'Eo, comme le croient au demeurant la plupart des auteurs, et c'est manifestement la forme Egovarri utilisée par Humboldt et lue par Emile Littré, et non pas celle de Mayhoff que la plupart des chercheurs utilisent encore couramment de nos jours, qui est assurément la forme correcte étant donné que toutes les formes médiévales citées au début plaident en faveur de cette hypothèse : à partir d'une forme Egivarri on ne s'explique pas les formes médiévales Eube et Euve. En revanche, si on part d'une forme Egovarri, tout s'éclaircit en ce qui concerne l'initiale de ce nom : Egov[arri $]>E u v->E u b->O b$-, la chute du -g-intervocalique étant un phénomèn de phonétique galicienne.

25. Ce que nous ne savions pas alors expliquer, et que manifestement personne n'avait su expliquer, était la finale -varri. Humboldit, il est vrai à une époque considérée comme pré-scientifique, avait pensé qu'on avait affaire au nom d'une ville et que la finale -varri était le biscaïen barri, "neuf, nouveau" et en conséquence qu'il s'agissait d'un nom euskarien : ego-barri, "nouvelle demeure". C'était bien entendu faux mais il avait toutefois raison sur un point: il s'agit effectivement d'un nom euskarien. On peut dire, sans exagérer, que cette découverte bouleverse en partie nos connaissances sur la Galice romaine - car à l'époque de Pline nous n'avons plus affaire à une époque dite pré-romaine. La forme latinisée Egovarri doit clairement être comparée à la forme médiévale Navarri : si cette dernière est une forme latinisée signifiant "les Navarrais" alors la forme Egovarri signifie tout simplement "les Egovarrais" et doit s'analyser en conséquence ainsi : Egob(e)-arr, avec le suffixe basque indiquant l'origine -arr, $-i$ étant la déclinaison latine. On retrouve la forme ${ }^{*} E g o b e$ (d'où est issu le nom de la paroisse galicienne appelée Obe $<$ Ove $<$ Euve $<*$ Egobe). Les Egovarri de Pline étaient donc "les habitants du lieu appelé *Egobe, les Egovarrais" et le nom de l'antique localité luquoise (aujourd'hui paroisse) appelée "Egobe (aujourd'hui Obe) devait alors signifier "au pied, à l'embouchure de l" Ego", la forme de cet hydronyme galicien ayant continué à évoluer: ${ }^{*} E g o>E O$.

26. En guise de conclusion, on constatera que la démonstration peut sembler longue mais cela provient du fait qu'il a été commis au cours du temps, on l'a dit, plusieurs erreurs, principalement de lecture, qui ont rendu opaques des faits relativement simples au départ. La conclusion de tout ceci semblera banale au profane qui ne s'intéresse que peu à ces questions, mais elle revêt une grande importance pour les Études Basques car ces faits contredisent en partie les théories. actuelles sur l'étendue vers l'ouest de la Cordillère Cantabrique des parlers préindo-européens au cours de l'Antiquité. Il semble désormais apparaître un fait fort simple au demeurant : chez les Callaïques du conuentus de Lugo, c'est-à-dire grosso modo dans le territoire constituant l'actuelle Galice, il y avait au cours de l'époque romaine certaines populations indigènes qui utilisaient les suffixes -arr et -be, indiquant l'un l'origine et l'autre la position, des suffixes qui se retrouvent encore de nos jours en basque moderne avec la même fonction.

27. Les dires de Pline de l'Ancien (Nat. Hist., III, 13) prennent alors un poids. tout à fait remarquable: "La juridiction du conuentus de Lugo comprend seize peuples, qui à l'exception des Celtiques ${ }^{62}$ et des Lémaves, sont d'origine obscure et ont des noms barbares, mais constituent néanmoins une population de 166000 individus libres". En outre, cela expliquerait également un fait de phonétique galicienne qui n'a toujours pas reçu une explication satisfaisante. En galicien, il 
existe, comme, entre autres, en basque, une tendance à éviter les $r$-à l'initiale et à les remplacer par arr-, c'est-à-dire avec a prothétique. On a attribué ce phénomène à un substrat ibérique, fait que les auteurs galiciens dits "celtisants" se sont toujours efforcés de nier.

\section{9) Les théories d'Ernst Gamillscheg}

28. Notre hypothèse n'est pas entièrement nouvelle. Elle avait déjà été suggérée, quoique pas exactement dans les mêmes termes, par le romaniste allemand Ernst Gamillscheg : d'après celui-ci, il aurait existé à l'époque pré-romaine et même romaine une unité linguistique allant depuis la Galice jusqu'aux Pyrénées Orientales. Mais sa théorie ne fut pas acceptée par la communauté scientifique.

29. Il faut dire, comme le rappelle Fredrick H. Jungemann ${ }^{63}$, que la plupart de ses théories étaient abstruses. La plus curieuse concerne les Cantabres du VI ${ }^{\circ}$ siècle. Selon cet auteur, c'est le roi wisigoth Léovigild qui aurait soumis définitivement les Cantabres dont l'origine était, toujours d'après lui, ligure et qui n'auraient jamais été complètement vaincus par les Romains. En 579, le nom de Cantabria est remplacé par celui d'Autrigonia. Selon Ernst Gamillscheg, ce changement s'explique ainsï: les Autrigons, qui étaient à cette époque sous le joug des Cantabres, leurs voisins et ennemis, aidèrent Léovigild à conquérir le territoire de ces derniers qu'ils reçurent alors en récompense. Afin d'éviter de nouvelles révoltes, les Wisigoths déportèrent une partie des Cantabres en Galice qu'ils avaient pour lors reprise aux Suèves. Entre temps, le reste des Cantabres se ceraicnt confuis dans les montagnes en compagnie des Vascons - qui pour lors avajent également été vaincus par les Wisigoths - et auraient envahi avec eux le versant aquitain. Cela aurait engendré un superstrat linguistique cantabre en Galice et dans les Pyrénécs. E. Gamillscheg expliquait ainsi le phénomène de nasalisation des voyelles que connaissent conjointement le galaïco-portugais, le basque et le gascon. Cependant, cette hypothè est considérée par tous les auteurs comme étant non fondée.

30. Toutefois, malgré toutes les thćories quelque peu fantaisistes qu'il avait émises, Ernst Gamillscheg avait manifestement vu juste sur un point, en partic du moins. Il y avait assurément en Galice, à l'arrivée des Romains, des populations qui non seulement utilisaient des langues préceltiques, ce qu'au demeurant on savait déjà, mais de surcroît que certaines de ces langues contenaient, ce dont on doutait fortement il y a encore peu, des éléments que l'on peut appeler pré-indoeuropéens de type euskaroïde. Ce qui nous autorise à supposer qu'il s'agissait probablement de langues apparentées, de loin ou de près, au proto-basque. En revanche, la supposée unité linguistique, allant depuis la Galice jusqu'aux Pyrénées Orientales, mentionnée par Ernst Gamillscheg est plus que douteuse. En réalité, il devait exister plusieurs langues, certaines devaient même cohabiter sur un même territoire, et cela tout le long de la cordillère, tant: cantabrique que pyrénéenne.

\section{0) Similitudes toponymiques galaïco-basques et cantabro-pyrénéennes}

L'examen ultérieur de plusieurs autres documents, certains nouveaux, nous permet, outre quelques suppléments d'informations, de compléter la liste des toponymes cités dans notre dernier ar.icle ainsi que d'apporter quelques rectifications aux diverses analyses linguistiques que nous avions alors proposées. 
31. Aldai : une hauteur de la localité d'Outeiro de Rei (Lugo) a pour nom Aldai $(385 \mathrm{~m}$ ) d'après l'Institut Géographique National espagnol (IGN, échelle, 1:25.000, Rábade, feuille $\mathrm{n}^{\circ}$ 72-II). D'après Alfonso Irigoyen, un quartier de Baracaldo (Biscaye) a pour nom Aldai (cf. également le patronyme basque Aldai ou Alday). En outre, il signale un "Aldana, cuesta de Santurce, 1863, barrio de Zaramillo (Güeñes)', este ultimo mostrando la forma sin caida de $-n$ - intervocalica, de donde procede aldai y alde, sul. althe, formas vascas conocidas, del bajo lat. *altana" ${ }^{4}$. Plusieurs montagnes et endroits d'Alava portent également ce nom : Alday, montagne d'Abecia, de Elosu et d'Acosta, quartier d'Amurrio et lieu-dit d'Arrieta (Treviño). L'évolution d'un autre toponyme galicien (cf. cartulaire de Lorenzana) semblerait confirmer l'hypothèse d'Irigoyen : in Uilla Noua de Archaa, $1177>$ Uilla Noua de Archay (moderne Arca, Abadin, Lugo), la forme Archaa étant probablement issue d'une ancienne forme *Archana, ce qui permet de supposer par ailleurs, en ce qui concerne l'oronyme luquois, une évolution semblable et tout à fait vraisemblable *Altana $>$ Aldana $>*$ Aldaa $>*$ Aldae $>$ Aldai (forme actuelle) comme probablement dans Aspae $>$ Aspai (cf. infra).

32. Andelo : parmi les Vascones, Pline (Nat. Hist., III, 24) cite le peuple des Andelonenses, de la cité d'Andelo, l'ethnique se lisant aussi dans CIL II, 2963. Pour cette cité vasconne, Ptolémée (II, 5) écrit "Av $\delta \eta \lambda ం \zeta$, moderne Muruzábal de Andión, uia de Andione, 1060, au sud de Puente la Reina (Navarre). A Andión se trouvent les ruines d'une importante localité romaine. Un lieu de la province d'Orense a pour nom Andelo (localité de Peroja, paroisse de San Vicente de Graices), autrefois eu Gomez Eanes, cavalleyro d-Andello, 1296 (cartulaire d'Oseira). Dans un document galicien du XI' siècle (cartulaire de Sobrado), on lit : in terra Parrice Uillanoua, Bacim, Uillar Plano, Sancto Uincentio, Castro Potamio, Uasconos, 1037. Ce dernier représente manifestement l'ethnonyme Vascones. II s'agissait probablement d'un établissement vascon postérieur à la Reconquête, cf. également le hameau galicien appelé Bizcaia, ancienne graphie espagnole Vizcaya (et non Viscaya comme nous l'écrivions par erreur, cf. "Bizkaia, caserío de Ranero (Carranza), 1671, Bizcaya" cité par Irigoyen"). A côté du mont appelée Aldai (Lugo, cf. supra), un endroit montagneux est également appelé Os Bizcaios (< *Os Bizcainos, "les Biscaïens" suite à la chute normale en galicien $\mathrm{du}-n$ - intervocalique, ce terme désignant à une époque les Basques en lieu et place de l'ancien terme Vascones). Alfonso Irigoyen rappelait que le nom du monte Igueldo de Saint-Sébastien (cf. la montagne galicienne appelée, comme l'avions déjà signalé, Gueldo et l'asturienne Agueldo, $1248 \mathrm{~m}$ située à côté d'un village asturien également appelé Treviño se trouvant à $700 \mathrm{~m}$, cf. IGN, Camaleño, 1:25.000, 81-I/16-6) apparaît dans un document du moyen âge accompagné du terme Bizchaya pour désigner la montagne : concedo totum quod in iheldo Bizchaya ${ }^{\text {s6 }}$. Par le passé, ce mot a probablement dû être utilisé dans tout le Nord de la péninsule ibérique avec le sens de montagne, ce qui expliquerait sa présence en Galice. Jean-Baptiste Orpustan rappelle que "l'un des mots les plus anciennement attestés est sûrement bizkai qui parait dérivé sur la même base que bizkar, 'dos, hauteur, sommet' et avec le même sens : 932 bizcahia (avec l'aspiration antihiatique des premiers textes) nom de la province de Biscaye, mais très répandu sur tout le territoire pour nommer des sommets (1171 la vizcaia de sobre sant jayme del mont : la formule indique que, comme d'autres mots basques, il avait été emprunté par le roman médiéval; de même 1193 baigorri vizcai)" ${ }^{367}$. 
33. Aralde : un village de Lugo et un autre de Pontevedra ont pour nom Aralde. Luis Michelena ${ }^{68}$ cite ce nom parmi ceux des pecheros ou roturiers de l'Ordre de Saint-Jean en Navarre apparaissant dans un document du XIII ${ }^{e}$ siècle. Dans la partie consacrée aux "villages de la Montagne", le document fait état d'un Lope Araldeco ou Lope d'Aralde, autrement dit d'un certain Lope originaire d'un lieudit ou d'une maison appelé Aralde au même titre qu'il est également fait état dans ce document médiéval d'un Eneco Iturbideco ou Eneco d'Iturbide. Il est probable que nous avons ici affaire au même nom que celui apparaissant en Gialice. Or, il est également possible qu'il s'agisse d'un nom germanique puisqu'il s'avérerait douteux que les Aralde galiciens soient d'origine basque. Un village portugais a pour nom Baralde (Ponte do Lima, district de Viana do Castelo) dont l'origine germanique ne fait guère de doute d'après Joseph $\mathrm{M}$. Piel ${ }^{69}$, ce qui nous laisse supposer que les deux Aralde galiciens le sont également.

34. Arán: comme nous l'indiquions dans notre dernier article, plusieurs lieux galiciens portent ce nom. Nos recherches nous permettent de citer la forme ancienne de l'un d'entre eux, probablement celui situé dans la province d'Orense : in loco qui vocantur Aran, in termino de Canba, 1240 ; in monasterio Ursarie, do et offero in presenti eidem monasterio totum quinionem meum quod habeo vel habere debeo in loco qui vocatur Aram, in terra de Canba, 1245 (cartulaire d'Oseira).

35. Aranga: la plus ancienne mention du nom de ce bourg de La Corogne date de 966 (10-XII) et non de 1178 comme l'avions indiqué : sic omnia uobis concedo sicut et uos mihi simul uestro et nostro castello Aranga cum omne sua prestantia (cartulaire de Sobrado). Le nom est attesté à plusieurs reprises et toujours sous la même forme : una cum fratres et sorores de Aranga, 1016. La signification de ce nom est inconnue. Le patronyme Aranga que l'on trouve en Amérique du Sud est un nom de famille d'origine galicienne et non pas basque, contrairement à ce qu'on croit souvent, quoique à la rigueur il puisse s'agir d'un patronyme bascogalicien. Dans ce cas, il faut alors faire appel à la généalogie pour déterminer l'origine exacte des individus le portant.

36. Aranza: deux localités galicienncs, l'une de Lugo et l'autre de Pontevedra, portent ce nom dont la signification n'est pas connue. Des recherches ultérieures nous permettent de signaler la forme ancienne du nom d'au moins l'une de ces localités, probablement celle de Lugo : in suas casas hic in Naraia quod eicisent de Pena ante iudice Vermudu Menendizi hic in Aranza, (13-XII-1058, cartulaire de Samos, Lugo). Même remarque que pour le nom précédent : le patronyme Aranza est un nom de famille basco-galicien. Il faut par conséquent et nécessairement faire appel à la généalogie pour déterminer l'origine exacte des individus ainsi nommés. D'autre part, ce nom galicien n'a aucun rapport, comme l'avions déjà indiqué dans notre dernier article, avec celui du village navarrais appelé Araniza (Cinco-Villas), autrefois Aranaz, 1280.

37. Arga / Argá : comme nous l'indiquions, un village de Lugo a pour nom Argá (oxyton), nom qui semble se rencontrer dans celui de la rivière navarraise appelée Arga (paroxyton). Le nom se retrouve également, sous une forme vraisemblablement paroxytone, dans le nord du Portugal, dans la région de Braga. Il s'agit du nom d'une zone montagneuse culminant à $823 \mathrm{~m}$. : Serra de Arga. La signification de ce toponyme galaïco-basco-portugais est difficile à établir, il s'agit probablement d'un terme pré-latin < *arga, "brillant, blanchâtre", cf. top. 
asturiens L'Argaxá, Argaxo, (Tierra) l'Arguexu, la montagne asturienne appelée La Argarama, $1818 \mathrm{~m}$, etc. Nous signalions également qu'une montagne et une rivière galiciennes avaient pour nom Argán. Une origine euskaroïde semble toutefois douteuse pour ce dernier, quoique plausible : < $* \operatorname{arr}(i)+$ gain. Nous n'avons pas pu retrouver les anciennes formes de tous ces noms, ce qui rend difficile leur analyse.

38. Argote : un village de La Corogne, comme nous l'avions déjà signalé, a pour nom Argote. La forme ancienne n'est pas connue. Un autre village galicien de La Corogne s'appelle Argonte, autrefois in villa Argonti, 955 (cartulaire de Sobrado) et deux villages portugais portent le même nom : l'un Argonde (Felgueiras, district de Porto) et l'autre Argonte (district d'Évora). Il s'agit dans les trois cas, indique Joseph M. Piel ${ }^{70}$, de noms d'origine germanique. Et il en est très probablement de même pour la variante Argote. En Pays Basque, un lieu-dit alavais est appelé de nos jours Argote (Treviño), autrefois c'était le nom d'un village : Argote, 1025, Argot, 1257. Ce nom basque n'ayant jamais pu être expliqué à partir de la langue basque, il est extrêmement probable qu'il s'agit dès lors, à l'instar de son homonyme galicien, d'un nom d'origine germanique. En outre, le patronyme Argote pouvant être de nos jours porté par un Portugais (cf. l'érudit portugais du XVIII siècle Jeronymo Contador de Argote), un Galicien et un Basque de souche, il est par conséquent indispensable de faire appel à la généalogie si l'on veut connaître la véritable origine des individus ayant ce nom pour patronyme.

39. Arros : une juridiction et un archiprêtre de La Corogne, et non un village comme nous l'indiquions par erreur dans notre dernier article, porte le nom d'Arros (il s'agit manifestement d'un paroxyton). D'après nos recherches, le nom est déjà attesté dans un document suève du VI ${ }^{e}$ siècle connu sous le nom de Parochiale. Mais il s'agit assurément d'une interpolation du XII ${ }^{c}$ siècle ${ }^{71}$. On pense d'ordinaire que ce nom galicien est en rapport avec celui d'un peuple du conuentus de Lugo appelé Arroni (Pline, IV, 111). Ce peuple considéré d'origine préceltique aurait occupé les régions d'Ortigueira situées à l'extrême nord de la province de La Corogne, ce qui correspondrait à la juridiction et à l'archiprêtre médiévaux d'Arros. Nous avions comparé ce nom, entre autres, au nom du village bas-navarrais appelé Arros ainsi qu'à ceux des villages pyrénéens ayant le même nom : Arrós (Alto Paliars, Lérida, Catalogne) et Arrós (Val d'Aran, Lérida, Catalogne).

40. Arteaga : ce nom se retrouve fréquemment en Pays Basque : on a le village navarrais appelé Arteaga (vallée de Allín, Estella), les villages et quartiers de Biscaye appelés respectivement Arteaga (quartier de Derio et de Zamudio), Arteaga-Uria (quartier de Gauteguiz de Arteaga) et le village appelé ArratiArteaga (en espagnol Castillo-Elejabeitia). Le sens est clair : "lieu de chênesverts". Or, d'après l'Institut Géographique National espagnol (IGN, 1:25.000, Arteixo, feuille $\mathrm{n}^{\circ} 45-\mathrm{I}$ ), une "montagne" située à environ $7 \mathrm{~km}$ au sud de la ville de La Corogne a pour nom Arteaga. Une erreur de l'IGN est à écarter ${ }^{72}$. La deuxième possibilité serait de supposer que le nom de cette éminence de La Corogne, une des plus élevées du secteur ( $244 \mathrm{~m}$ ), est un patronyme basque devenu un oronyme. Cependant, il s'agit d'une zone montagneuse inhabitée d'après l'IGN et le nom des autres hauteurs ne parait pas d'origine patronymique : Monte Runs $(184 \mathrm{~m})$ à $2 \mathrm{~km}$ au nord-est du mont Arteaga, celui d'O Picoto (162 m) 
situés à $1 \mathrm{~km}$ à l'est, les autres montes s'appelant: A Raña (142 m.), Filgueiras (id., 142 m.), Folgueira $(270$ m.), Coto de Fonte Mayor $(181 \mathrm{~m}$.). Les villages situés au pied de la "montagne" Arteaga s'appellent, quant à eux, Orro, Toroño (cf. la montagne d'Alava appelée Toloño, $1271 \mathrm{~m}$.) et Ledoño avec chute courante de la nasale en galicien ${ }^{*}$ Lendoño $>$ Ledoño ${ }^{73}$. Comment pourrait-on dès lors expliquer cet étrange oronyme corognois Arteaga? Le principal village du secteur est situé à environ $5 \mathrm{~km}$ à l'ouest de cette "montagne" et a pour nom Arteixo (autrefois en espagnol Arteijo, situé à environ $9 \mathrm{~km}$ au sud-ouest de la ville de La Corogne). Il existe plusieurs toponymes galiciens en art-inexpliqués : Arteixo (et la localité asturienne d'Artedo), Arteixiña (lieu-dit de la paroisse de Robledo, localité da Rúa, Orense), Artes (paroisse de San Xurxo de Artes, Carballo, La Corogne) et Artes (lieu-dit de la localité de Ribeira, La Corogne, cf. le toponyme catalan Artés et le landais Arthez-d'Armagnac). On peut uniquement, dans l'état actuel de nos connaissances, postuler pour cet oronyme de La Corogne une protoforme *Arteaca $>$ Arteaga ${ }^{74}$.

41. Aspai : il s'agit du nom d'un village de Lugo que nous avions déjà mentionné. Il est situé au pied d'une montagne de $735 \mathrm{~m}$. Des recherches ultérieures nous permettent d'en citer la forme ancienne : unum casale in parrochia sancte Eugenie in villa que vocatur Aspay, 1234, in ecclesia sancti Salvatoris d. Pinaria, que iacet in terra de Asma. Quicquid vero in predicta ecclesia habeo ex successione patris mei Garsie Roderici, militis de Aspay, 1242, Iohannis Fernandi de Aspae, 1242 (cartulaire d'Oseira). En outre, il existe deux villages appelés Asma dans la province de Lugo. Celui dont la forme ancienne est mentionnée ci-dessus et un autre dont nous avions déjà fait état et: dont les formes anciennes sont citées par Olano Silva : in nasue ( = nasbe), 747?, Asma, 832, territorio Assue ( = Assbe), Asme, 871, Asua ( = Asba), Asma, 897, ambas Asmas, 1173, il s'agit de nos jours du nom d'un village et d'une rivière de Lugo appelés Masma. Signalons également qu'un village de la province d'Alicante situé dans une zone montagneuse à $12 \mathrm{~km}$ au nord-ouest d'Elche (autrefois Ilicis, ancien territoire des Ibères appelés Contestani) a pour nom Aspe.

42. Azanza: au moyen âge, comme le rappelle Jean-Baptiste Orpustan, Cambo (Labourd) était connu "surtout par le nom de la maison noble Azantza". Il ajoute "d'étymologie apparemment basque mais obscure", cf. autrefois Sancho de Açança, 1249, Petrus de Assansa, 1311 d'après Eugène Goyheneche. En Galice, les documents médiévaux mentionnent un monastère, situé probablement dans la province de Lugo: Sancte Marie de Azanza, XII' siècle (cartulaire de Lorenzana). En outre, un village de Lugo appelé de nos jours Anzas et situé dans la région de Ribadeo (à l'extrémité nord-est de la Galice) s'appelait autrefois Asanza : In Asanza ecclesiam Sancti Vicenti cum suis adiunctionibus, 7-VI-969; ego, Urraca Ueremudiz, facio cartam testamenti de media ecclesia Sancta Maria de Asanza, 1132 ; ego, Urraca Ueremudiz [...]. Tali modo concedo uobis mea ecclesia sancta Maria de Asança, 26-X-1132 (cartulaire de Lorenzana). Citons également le village navarrais appelé d'Azanza (vallée de Goñi, Estella), autrefois Asança, Assança, 1233, 1280).

43. Baiona: dans notre dernier article, nous adhérions aux dires d'Eugène Goyheneche qui voyait dans ce nom galicien le nom attribué à "un repeuplement, [à] une ville neuve, fondée aụ même endroit qu'Erizana (terme ancien) dépeuplé par les Invasions [car] on donnait à ces villes, souvent un nom déjà porté par une 
autre ville, plus célèbre ou plus ancienne. Il n'est donc pas impossible qu'en 1130 Alphonse VIII ait donné ce nom à Bayona [graphie espagnole] de Galice, en se souvenant de notre Bayonne" ". Cependant, les faits paraissent moins clairs que prévu. Ce nom galicien apparaît au début du XII ${ }^{\circ}$ siècle. Or, le territoire où est située la ville de Baiona est chrétien depuis le début du VIII ${ }^{e}$ siècle étant donné que la domination musulmane sur ce territoire (du moins l'emprise théorique car en réalité l'influence arabe en Galice et dans la partie nord du Portugal fut inexistante) dura à peine plus de vingt ans. En effet, les Arabes et les Berbères envahirent la péninsule en 711. En 739, sous le règne d'Alfonse I, la "frontière" entre le monde chrétien et le monde musulman était déjà située sur le fleuve Miño, c'està-dire sur l'actuelle frontière entre la Galice et le Portugal, et sous le règne d'Alfonse III (866-910) la limite était le fleuve Douro qui traverse la ville de Porto ${ }^{77}$. En conséquence, Baiona n'a pas pu être repeuplée au XII. siècle puisqu'à l'époque elle était déjà chrétienne depuis quatre siècles, quoique cela ne soit pas, en théorie, impossible. Lénigme semble devoir perdurer puisqu'on ne sait toujours pas exactement pourquoi cette ville de Pontevedra porte le même nom que I'ancienne capitale du Labourd. Toutefois, il est posible qu'Eugène Goyheneche ait vu juste, c'est-à-dire qu'au XII' siècle, on rebaptisa, pour des raisons qui nous échappent, cette ville galicienne en souvenir de la cité basque dont le prestige était considérable à l'époque. La seule certitude est qu'au XII ${ }^{e}$ siècle l'Empereur Alphonse VII (1126 - 1157) dit "Alphonse le Batailleur", qui en 1129 arait assiégé Bayonne (Labourd), ordonna, par un édit du 27 juillet 1130 , le remplacement du très ancien nom de la localité d'Erizana par celui de Baiona, peut-être en souvenir de ce siège

44. Bờp $\delta 0 \lambda \lambda o$, en latin Varduli ou Vardulli (Mela, Choro., III, 15, Pline, Nat. Hist., III, 26, 27) : les ancêtres grosso modo des actuels Guipuscoans étaient connus dans l'Antiquité sous le nom de Vardules. Strabon (Géogr., III, 4, 12), dont l'oeuvre se base en grande partie sur les écrits de Posidonius d'Apamée ${ }^{78}$ qui rédigea une partie de son oeuvre après 72 av. J.-C., mentionne les "Bardyètes, qu'on appelle aujourd'hui Vardulles". Or, fait curieux, Pline (Nat. Hist., IV, 118) cite, parmi les peuples de la Lusitania, "les Turdules, dits Bardules" (Turduli qui Barduli [cognominatur] $)$. Le seul auteur, à notre connaissance, à mentionner ce fait est Julio Caro Baroja ${ }^{79}$. Toutefois, deux lectures du texte de Pline sont possibles : l'une, celle de Mayhoff, opte pour une leçon Bardili (quoique cet auteur signale également dans ses notes la forme Barduli). En revanche, Emile Littré, qui se base sur le texte du jésuite Hardouin, rapporte une forme Barduli. Les Turdules était à l'origine un peuple ibère établi dans la région de Cordoue et sur le bas-Guadalquivir. Ils étaient peut-être apparentés aux Turdétans. Une partie de ces Turdules s'installèrent en Lusitanie où Pline (Nat. Hist., IV, 113) cite les Turduli veteres surnommés, on l'a vu, Barduli. Strabon (Géogr., III, 3,4) raconte en effet comment les Celtici - dont il ne faut pas confondre le nom avec celui des Celtes à proprement parler - s'étaient installés en Galice, à l'époque de Strabon cet événement devant être encore relativement: récent. Celui-ci rapporte en effet que les Celtiques ou Celtici (le sens serait "apparentés aux Celtes, qui ont la manière des Celtes") du bord de l'Anas [l'actuel fleuve appelé Guadiana < wada + ana, "Ia rivière Ana" en arabe], "ayant participé aux côtés des Turdules à une expédition militaire dirigée contre cette région [la Galice], ils se révoltérent après avoir franchi le cours du Limaeas [actuel Lima, nord du Portugal]. A la suite de 
cette révolte, comme ils avaient par surcroît perdu leur chef, ils seraient restés dans la contrée [en Galice] en s'y dispersant".

45. Beade : le nom du village de: Santa Maria de Beade (Orense) est attesté au moyen âge sous la forme Sanctae Mariae de Vilate, 1112. Nous avions, à l'instar de Gifford, comparé ce nom au nom d'un col navarrais appelé Velate (graphie basque Belate). Pline (Nat. Hist., IV, 33) cite parmi les peuples aquitains les Vellates dont le territoire n'a pas pu être identifié. Certains auteurs ont proposé de voir dans le nom navarrais un souvenir de ce peuple et de faire de ce col navarrais la frontière entre les Aquitani et les Vascones, ce qui n'est pas impossible. Si cela devait être le cas, alors l'étymologie basque que l'on attribue d'ordinaire au toponyme navarrais Belate ( < bela- + ate < bele + ate, "porte, passage des corbeaux") serait erronée. Il est probable, en effet, que le nom de peuple Vellates est un nom d'origine celtique étant donné qu'il désignait également un peuple celte originaire de la région italienne du Pô : les Veleiates (Pline, Nat. Hist., III, 116).

46. Ibia / Ibias / Ibias : dans les Asturies occidentales on trouve une rivière appelée rio Ibias, manifestement sans accent (IGN, Degaña, 1:25.000, 100-II) traversant la localité asturienne de Degaña située à $837 \mathrm{~m}$ (cf. le toponyme alavais et le patronyme basque Egaña < egi-gaiña où egi signifie "línea de los montes, ladera", selon L. Michelena ${ }^{80}$ et correspondant parfaitement à la situation géographique de cette localité asturienne). En Galice, dans la localité de Barreiros, province de Lugo, on trouve un ruisseau et un hameau appelés Ibia, autrefois unde in directo ad Sancto Laurencio unde ad Ibia et per iuga montis super Coarcos uia, 17-VI-969; per inga montis usque Ibia et sicut determinatur per circuitu omnem cautum usque in flumine Masma, 18-V-1087 (cartulaire de Lorenzana). Une autre petite rivière de Lugo s'appelle également Ibias. Un village de La Corogne et un autre de Pontevedra ont aussi pour nom Ibia (sans accent tonique comme dans le cas de l'hydronyme asturien). Ces hydronymes galaïco-asturiens doivent sans doute être comparés au basque $i b i$, "ruisselet" en Soule, "gué" en Navarre (Lhande). D'après Lafon, le bas-navarrais ibi est issu d'un plus ancien $u b i$ conservé en labourdin (où on a aussi ibiri, ibide, ubide, "gué") suite à une dilation régressive ${ }^{81}$. Toutefois, la question semble être complexe. Hubschmid ${ }^{82}$ ne croit pas à une évolution $u b i>i b i$ à cause de la grande diffusion dans la péninsule ibérique des toponymes $i b i-$, Jean-Baptiste Orpustan indiquant par ailleurs qu"en Pays Basque "la dominante [est] clairement $i b i$ : 1047 oreriuia, 1086 stigarrivia, 1098 escaribia, 1180 undarauia, 1199 yviazabal, 1308 olhayvie, ibyete" ${ }^{" 83}$, etc. D'après Michelena ${ }^{84}$, la propagation des toponymes Ibia dans la toponymie de la péninsule ne constitue pas un argument suffisant pour différencier d'un point de vue étymologique ibi et $u b i$. Les toponymes Ibia(s) laisseraient également supposer que l'existence de l'"article" $-a$ est plus ancienne qu'on ne le croit d'ordinaire comme nous le verrons dans un autre article à paraître dans Fontes.

47. Igon : Comme nous l'indiquions dans notre dernier article, on a en Béarn un village appelé Igon (canton de Nay-est), autrefois Ygon, 1385. Un autre village béarnais a pour nom Eygun (canton d'Accous), autrefois Igun, 1449. L'origine de ce nom est considérée d'ordinaire comme pré-indo-européenne. En Aveyron ${ }^{85}$, on trouve également un autre Igon (dans le Tarn, on a un lieu appelé l'Igal, cf. le village navarrais appelé $\mathrm{Igal}$, en basque Igari, dont la signification est inconnue, autrefois Igali, 1085, Igal, 1174). En Galice, on rencontre un village appelé Igón (Lugo). Des recherches ultérieures nous permettent en outre de citer une paroisse 
du même nom dans la province d'Orense : San Cristóbal de Regodeigón (localité de Beade), c'est-à-dire < gal. rego, "ruisseau" de (E)igón, autrefois Aygon, Eigon, 1219, Eygon, 1223, 1226, 1242, Eygun, 1249, Eigom, 1251, Eygum, 1253, in caminum quod vadit ad Eygun, 1253, Eygon, 1259 (cartulaire d'Oseira).

48. Láncara / Lángara : comme nous l'avions déjà indiqué, un ancien village d'Alava s'appelait Langara, 1025, moderne Nanclares de Gamboa selon López de Guereñu, cf. les lieux-dits alavais : Langarabidea, Langarabide, Langararabidea, Langarasaspia. J. Hubschmid ${ }^{86}$ cite plusieurs toponymes où on rencontre un suffixe atone '-ara tels que Brácara (Braga), Lózara (Lugo), Tállara (La Corogne), etc. Pour notre part, citons : Rio Záncara (20 km à l'est de Cuenca, Castille-La Manche). Dans notre dernier article, nous citions le village de Lugo appelé Láncara, autrefois per termino de Elarin et per termino de sancto Vicentio de Lancara, 1059 (cartulaire de Samos). Nous indiquions qu'en basque la sonorisation de l'occlusive après $n$ est normale : Láncara > Lángara. Nos recherches nous permettent également d'en citer également une variante en Estrémadure : le village et la rivière de Lácara (44 km à l'est de Badajoz, cf. l'ancienne localité d'Alava appelée Badayoz, autrefois Badajoz, 1463). En outre, nous en avons trouvé d'autres en Galice : un hameau situé à côté de la ville de Betanzos (IGN, Betanzos, La Corogne, 1:25.000, 45-II/5-5) est appelé Lángara (avec une séquence $-n g$ - au lieu de - nc-). Toujours au nord de Betanzos, on trouve également un lieu-dit appelé Pazo de Láncara.

49. Urrós / Urros / Urro(t)z / Urriés / Urria / Urriellu / Urrialdo : dans notre dernier article nous indiquions qu'un hameau de la localité galicienne d'Allariz (Orense) a pour nom Urrós (oxyton). Des recherches ultérieures nous permettent de citer deux autres localités du même nom dans le Nord-Ouest du Portugal : un Urrós (accentué manifestement sur la dernière syllabe) situé à $24 \mathrm{~km}$ au sudouest de la ville frontalière de Miranda do Douro et un Urros (sans accent, sauf erreur) situé à $76 \mathrm{~km}$ au sud-ouest de ce même Miranda do Douro. Gifford avait comparé l'Urrós galicien avec les navarrais Urrotz (vallée de Malerreka) et Urroz (Sangüesa). Nous citions pour notre part l'Urriés aragonais mentionné par Rohlfs ${ }^{87}$ qui le faisait dériver d'un anthroponyme non attesté *Urrus. Il citait pour cela le nom de personne Urranus attesté en Espagne (Cuenca). Il doit s'agir dans tous les cas, comme le pensait Rohlfs, de noms à base anthroponymique. En tout cas, l'existence des toponymes portugais semble plaider en faveur de cette hypothèse. En outre, étant donné que Joseph M. Piel ne les cite pas dans son ouvrage consacré à la toponymie portugaise d'origine germanique, on peut supposer qu'ils n'ont pas une telle origine. Alfonso Irigoyen comparait les nombreux Urrea et Urria attestés en Aragon, ainsi que dans le nom d'un village de Burgos (proche de la vallée de Mena) appelé également Urria, avec les nombreux toponymes euskariens Urriategui, Urriaurra, Urricosola, etc. Alfonso Irigoyen semblait extrêmement étonné, en revanche, d'en trouver deux dans les Asturies centrales : le village d'Urria (municipalité de Pola de Somiedo) situé au pied d'une montagne de $1660 \mathrm{~m}$. et une paroisse appelée Santa María Magdalena de Urria (municipalité de Teverga) située dans une zone montagneuse culminant à $1419 \mathrm{~m}$. Cet étonnement, dont l'auteur ne faisait aucun mystère ("[es] perturbador que aparezca dos veces en Asturias", soulignait-i ${ }^{88}$ ), s'explique aisément. Il s'est développé au cours de ces dernières décennies dans le domaine des Études Basques, surtout parmi les chercheurs du Pays Basque méridional, un parti pris qui a quasiment été érigé en dogme, à savoir : au cours de l'Antiquité l'extension de la 
langue basque vers l'Ouest n'a pas dépassé, ou à peine, les actuelles Encartaciones biscaïennes (Biscaye occidentale). Cette hypothèse a fait école en Pays Basque. Elle est même devenue pour beaucoup une certitude - la plupart des auteurs du Pays Basque Sud ont pris toutefois la précaution de préciser que dans l'Antiquité le territoire de la langue basque recouvrait d'un point de vue géographique l'actuelle région basque, ce qui, pour les raisons que nous avons déjả indiquées dans notre dernier article, ne nous paraît pas invraisemblable, mais reste cependant non prouvé car il existe des indices nous permettant de penser que les Varduli et les Caristii n'étaient peut-être pas des proto-bascophones ${ }^{89}$, ce qui peut paraître paradoxal puisqu'on suppose par ailleurs qu'une partie des Asturies pouvait en revanche l'être. C'est qu'en réalité, il ne faut pas s'imaginer dans l'Antiquité des aires linguistiques compactes, mais au contraire des poches linguistiques différenciées et disséminées tout le long de la cordillère. Ainsi, Alfonso Irigoyen, ne pouvant pas expliquer la présence de ces Urria asturiens, avait alors pris la décision d'esquiver la question (il indiquait : "prescindimos, por ahora, de los [Urrias] asturianos"90). Or, il est probable que parmi les Astures transmontani, il existait des populations préceltiques de type euskaroïde, même à l'époque romaine (Pline, Nat. Hist., VIII, 166, signale que les Astures appelaient leurs chevaux Thieldones, c'est-à-dire $\theta i e l d-o n e s$, nom qui a été comparé, rappelle Julio Caro Baroja ${ }^{91}$, au basque zald-, $i$, "cheval"). La deuxième hypothèse consisterait à supposer que ces toponymes asturiens Urria ne sont pas de type euskaroïde, ce qui est également plausible, mais dans ce cas rien ne permet alors de dire que les basco-aragonais le soient. Une des plus hautes montagnes des Asturies (Pics d'Europe) a pour nom Pico Urriellu $(2519 \mathrm{~m}$.) où le terme Urriapparaît de nouveau, Urriello étant la forme espagnole et Urriellu la forme asturienne. Ce nom asturien doit être comparé au toponyme alavais Urrialdo, 1025, Urrialdu, 1702, village dont la dernière maison disparut en 1937 suite à un incendie d'après López de Guereñu. Le changement $-l d->-l l$ - étant très bien attesté (cf. au XVIII ${ }^{\circ}$ siècle la maison d'Anglet Landalde > Landalle), une évolution Urrialdo $>*$ Urriallo $>$ Urriello $>$ Uriellu serait tout à fait banale. Un autre village de montagne des Asturies occidentales a pour nom Uría. A côté on trouve la Sierra de Uria. Il faut noter que le patronyme Uria, au-delà de son étymologie première, n'est pas un nom famille basque à proprement parler, mais basco-asturien, ce qui explique pourquoi il est si courant dans les Asturies. Pour déterminer si un individu ayant ce nom est un Asturien de souche ou un Basque, il faut obligatoirement faire appel à la généalogie.

50. Ustariz/Ustarriz/Ustaritz/Ustaitze/Osteri(t)z/-riz<-rici<-ricus < reiks : en Galice, il y a une de nombreux toponymes finissant en -riz. Ce sont en général des noms germaniques composés de deux éléments, le deuxième étant reiks, gotique "prince", vieux haut-allemand rihhi, "puissant" d'après Marie-Thérèse Morlet $^{92}$, morphologiquement latinisé par la suite en -ricus > -rici génitif > -riz/ -ris. Certains semblent se retrouver en Pays Basque et sous une forme identique : le village navarrais appelé Oderi $(t) z<*$ (uilla) Oderici $<$ Odericus, attesté en 861 (Morlet ${ }^{93}$ ); en Galice on a Villaodriz (Lugo), autrefois uilla odorici, 1037 (cartulaire de Sobrado, mais il s'agit peut-être d"un autre Villaodriz situé dans la province de La Corogne), cf. également en Galice : Anderici, 989?, casale de Anderiz, s. d. prob. $\mathrm{X}^{\mathrm{c}} \mathrm{s}$. (cartulaire de Sobrado) et les toponymes navarrais Enériz, autrefois, eneriç, 1233 et Endériz, autrefois enderiz, 1257 (< prob. germ. Andricus cité par M.-Th. Morlet et Andericus cité par Boullón Agrelo ${ }^{85}$ avec par 
la suite en Navarre $n d>n n>n$ comme dans $*$ Garindoain $>$ Garinoain, autrefois Garinnoain, 1072), etc. Les hispanophones ont pour habitude d'accentuer ces noms galiciens sur l'avant-dernière syllabe, ce que ne font pas les galaïcophones qui accentuent toujours sur la dernière : cela explique pourquoi un Espagnol prononcera les toponymes galiciens Uriz, Oriz (cf. également le viliage portugais appelé Oriz),Alderiz, Baldariz, Esmoriz, Goiriz, Astariz (cf. le patronyme basque Dastaritz), etc. $\rightarrow$ Úriz, Óriz, Aldériz (cf. les toponymes navarrais identiques prononcés Úriz, Óriz et Aldériz en espagnol, basque Uritz, Oritz et Alderitz) Baldáriz, Esmóriz, Goiriz, Astáriz et un Galicien Uriz, Oriz, Goiriz, etc. sur la dernière. Les Espagnols prononcent l'Ustaritz labourdin $\rightarrow$ Ustáriz et Biarritz $\rightarrow$ Biárriz. En Galice, on a également un lieu de Lugo, comme nous l'avions déjà indiqué, appelé Ustariz (accentué sur la dernière) que les Espagnols prononcent par erreur Ustáriz et qui rappelle évidemment l'Ustaritz du Labourd et les Osteritz (accentué en espagnol Ostériz, autrefois Ostariz, 1280, prononciation basque Osteritz) et Ustaize de Navarre. López de Guereñu cite un Ustarriz alavais (avec $r r$ au lieu de $r$, suite probablement à un renforcement analogique de la vibrante) qui est, écrit-il, une fontaine de "San Vicente de Arana". La forme Ustaize est une forme populaire salazaraise, et d'après Salaberri ${ }^{\%}$ plus ancienne, du toponyme navarrais Ustés (forme romane), ce implique un plus ancien ${ }^{*}$ Ustariz > Ustaize avec -e paragogique. Nous ne nous prononcerons pas sur ces toponymes basques. Ce qui en revanche paraît probable est que l'Ustariz galicien est nom d'origine germanique : Austericus > *uilla Osterici (la forme aust- du premier élément de composition étant également attestée sous la forme ost-, cf. Morlet $^{97}$ ) > Osteriz $>$ Ostariz $>$ Ustariz. Tous ces toponymes galaïco-basques en -riz mériteraient qu'on leur consacrât une étude particulière. En ce qui concerne le Goiriz galicien (village de Lugo), Alfonso Irigoyen pensait y voir une forme patronymique issue du nom basque Goiri. Mais sa présence en Galice devant être toutefois expliquée, l'auteur concluait: "posiblemente difundido a partir del País

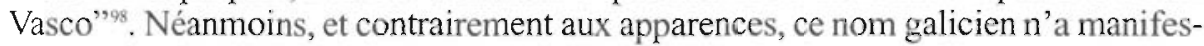
tement rien à voir avec le basque, quoique son étymologie ne semble pas encore être clairement et définitivement établie : Santiago de Goiriz, autrefois S. Jacobus de Quirice, 747 (date qui ne plaide pas en faveur d'une diffusion à partir du Pays Basque), en réalité devant être lu Cuirice $>{ }^{*}$ Goirice $>$ Goiriz selon Olano Silva ${ }^{99}$, Goeriz, 1128. Alfonso Irigoyen signalait que la forme ancienne qu'il citait est une falsification du XII" siècle : Ecclesiam Sancti Jacobi de Goiriz, 897.

Ces recherches devraient probablement être poursuivies car tout ce que nous venons de citer ne représente en réalité qu'un échantillon d'un sujet très vaste et relativement, du moins en Galice et dans les Asturies, peu étudié eu égard à ce qui se fait dans d'autres régions d'Europe. D'autant plus, on l'a vu, que le stock toponymique galicien est impressionnant. Cependant, pour mener à bien ces tâches, il faudrait probablement un nombre beaucoup plus grand de chercheurs comme le signalait déjà en 1973 René Lafon à propos de l'étude, cette fois-ci, des inscriptions ibères ${ }^{100}$.

\section{1) Une survivance linguistique apparemment inexplicable}

Oyharçabal résume la question de la survie de la langue basque "qui demeure sans réponse satisfaisante" de façon on ne peut plus claire : "pourquoi les Basques, qui durant des dizaines de siècles ont adapté et se sont appropriés, sans grande réticence semble-t-il, la substance des cultures matérielles et spirituelles 
apparues successivement dans cette zone de l'Europe, n'ont-ils pas également adopté de façon généralisée les systèmes linguistiques associés à ces cultures, comme cela a été le cas pour les autres populations?"

Pour essayer de répondre à cette question, il faut se remettre dans le contexte de la romanisation ayant eu lieu au début de notre ère. La survie du basque semble se jouer principalement entre le I ${ }^{\text {er }}$ et le $\mathrm{IV}^{e}$ siècle, bien que les Basques soient déjà en contact avec les Romains depuis le $\mathrm{II}^{\mathrm{e}}$ siècle av. J.-C. La logique demande, voire exige, pour des raisons que nous allons aborder, que la langue disparaisse à cette époque. Or, non seulement elle ne disparaît pas, mais, de surcroît, à partir du $V^{a}$ siècle, les Basques - et en conséquence leur langue - semblent être en pleine expansion. Comment expliquer un tel paradoxe? D'une part, il parait nécessaire d'avoir une vision d'ensemble et d'observer ce qui passe à cette époque chez les voisins des Basques, et notamment lors des guerres cantabres.

Orose (VI, 21, 1-11) et Florus (II, 33, 46-60) sont les deux historiens grâce auxquels nous connaissons le déroulement de ces guerres ${ }^{102}$. Orose raconte qu'en "l'an 726 de la fondation de Rome, étant empereur Auguste César consul pour la sixième fois, M. Agrippa pour la seconde fois, considérant le premier que tout ce qui avait été entrepris en Hispanie pendant deux siècles eût été vain si l'on permettait aux Asturiens et aux Cantabres, deux peuples très puissants de l'Hispanie, de continuer à se gouverner selon leurs propres lois, il ouvrit les portes du temple de Janus et en personne il se dirigea en Hispanie à la tête de l'armée". Florus écrit : "Presque toute l'Hispanie était pacifiée, sauf la partie des Pyrénées dont l'Océan proche venait baigner les rochers. Là, s'agitaient deux peuples trés puissants qui n'avaient pas été soumis, les Cantabres et les Asturiens". Dans ce conflit, outre la présence d'Auguste en personne, il fallut, d'après les spécialistes, dix ans de guerre (29-19 av. J.-C.), les meilleurs généraux de l'empire et l'intervention simultanée de sept légions ( $I^{a}$ Augusta, $I I^{a}$ Augusta, $I I^{a}$ Macedonica, $V^{\text {a }}$ Alaudae, VI $I^{a}$ Valeria Victrix, IX Hispania, $X^{a}$ Gemina) réparties en trois colonnes : l'une d'entre elles se dirigea vers la Galice - le rôle exact des Callaïques dans cette guerre n'est pas très clair pour les érudits, mais il est certain cependant que l'intégration de la Galice à l'empire ne se fit qu'à la fin des hostilités; Orose (VI, 21, 1-11) parle en effet de plusieurs combats "dans les régions extrêmes de la Galice"103 -, une autre légion se dirigea vers les Asturies et une dernière vers la Cantabrie, légions auxquelles il avait fallu ajouter autant de troupes auxiliaires conformément aux usages romains dont, entre autres, la Cohors IV equitata Tracum et la Cohors IV Gallorum, le nom des autres n'étant pas connu, soit au total environ entre 70000 et 80000 hommes d'après les chercheurs ${ }^{104}$. Par la suite, vu la tournure que prenaient les événements, Auguste dut également faire intervenir la flotte.

Une fois soumis, c'est-à-dire dix ans après le début de la guerre, les combattants cantabres qui avaient été faits prisonniers furent vendus comme esciaves et envoyés en Gaule. Mais par la suite, raconte Dion Cassius (IV, 11,3), ils tuèrent leurs maîtres gallo-romains et retournèrent en Espagne où ils recommencèrent la guerre en attaquant les garnisons romaines, ce qui provoqua un véritable scandale à Rome. Auguste, comprenant qu'il y allait cette fois du prestige et de la cré-dibilité de Rome, donna carte blanche à Agrippa, son meilleur général. Mais une partie de l'armée impériale, démoralisée, refusait désormais d'obéir et d'aller au combat. Après plusieurs victoires cantabres, une légion entière, probablement la 
$I^{a}$ Augusta, dut même être sévèrement punie pour l'exemple. Les Cantabres furent finalement à nouveau soumis et Agrippa fit exécuter tous les prisonniers adultes. Mais entre 37 et 41 ap. J.-C., sous l'empereur Claude, les Cantabres se révoltèrent une nouvelle fois. Rome dut intervenir de nouveau. Entre 55 et 60 ap. J.-C., Néron étant empereur, les Asturiens prirent également les armes provoquant une nouvelle intervention de l'armée romaine. Ces guerres du ${ }^{\text {Ir }}$ siècle sont mal connues des spécialistes.

Les Basques, en revanche, ne semblent pas avoir opposé de résistance à l'empire romain, ce qui a beaucoup intrigué les érudits. A aucun moment, ils n'interviennent dans ces guerres puisqu'aucune source ne les mentionne. Pour expliquer ce fait extrêmement curieux, certains auteurs ont mis sur pied une théorie fort séduisante et très convaincante comme le rappelle Henri Etcheto ${ }^{105}$ : "Par contre ce que l'on sait c'est que le territoire vascon se trouve au Ir siècle av. J.-C., bien plus étendu qu'il ne l'apparaît au moment de l'arrivée des Romains [ $\mathrm{II}^{\circ}$ siècle av. J.-C.] [...]. Il y a donc eu une expansion vasconne qui n'a pu se réaliser qu'avec l'accord et même à l'instigation des Romains. La difficulté est de savoir quand et pourquoi Rome a favorisé ce peuple. Le fragment XCI de Tite-Live et la mention de Strabon ne laissent pas de doute : l'extension du territoire vascon aux rives de l'Ebre s'est produite au cours du Ire siècle av. J.-C., au détriment des Celtibères qui tenaient cette région auparavant. L'explication en est facile : dans sa lutte contre les Celtibères, Rome a dû bénéficier de la part des Vascons d'une bienveillante neutralité voire peut-être d'un appui, pas assez conséquent toutefois pour que les sources daignent le relever. Les Romains, qui répugnent encore à ce moment là à une administration directe trop contraignante, préfèrent confier cette zone stratégique à un peuple qui ne représenterait pour eux aucun danger. C'est la fameuse théorie de "I'amitié romano-vasconne"".

Cette théorie, qui ne fait pas l'unanimité comme le rappelle $\mathrm{H}$. Etcheto, est cependant très en vogue parmi les auteurs autorisés, bien qu'elle ne puisse pas être prouvée à partir des sources antiques connues, mais uniquement déduite à partir d'un raisonnement logique. En outre, elle présente un avantage. Elle permettrait de résoudre l'énigme de la survie inexpliquée et apparemment inexplicable de la langue basque, survie qui, on l'a vu, a énormément intrigué les savants. Puisque ni l'isolement ${ }^{106}$, ni même la "non-indo-européennité" du basque (car il existait dans la péninsule d'autres langues non-indo-européennes qui, elles, ont disparu.) ne peuvent expliquer cette survie, il est possible de supposer que ce soit en fait la fidélité présumée des Basques envers Rome qui en serait la. principale raison. En contrepartie de leur dévouement, les Romains n'auraient pas cherché à anéantir la culture autochtone vasconne, ce qui expliquerait la survie du basque malgré une quantité d'emprunts lexicaux au latin tout à fait considérable car un fait semble être clair : si Rome avait voulu anéantir les Vascons, elle les aurait soumis quitte à s'y employer pendant des décennies comme ce fut le cas avec les Lusitaniens et les autres peuples du Nord de l'Espagne. Si elle ne le fit pas, c'est qu'elle n'en ressentait pas la nécessité. A la chute de l'empire romain, les Basques se seraient alors déchaînés. Leur supposée bienveillante neutralité et fidélité envers leurs mentors romains auraient laissé place à une rare virulence dont les Goths et les Francs eurent à subir les conséquences. Comment expliquer sinon cette subite agitation qu'attribuent unanimement aux Vascons les sources franques et: wisigothiques et, surtout, comment expliquer la puissance qui est alors celle des Basques? 
Afin de s'imaginer le problème qu'ils posaient et la force qui était la leur, il suffira de citer Renée Goulard ${ }^{107}$ : "[Dagobert] envoya sur place [en Wasconia] la plus forte des armées jamais levées dans son royaume, qu’i] confia au référendaire burgonde Chadoin. Bien évidemment Aeghyna le Saxon était parmi les généraux mais aussi ceux qui quelques années plus tôt avaient assassiné Brodulf, les ducs Amalgaire et Arimbert et le patrice burgonde Willibald, dix corps d'armée au total et des comtes munis de commandements, armée si importante qu'à son retour de Wasconia il suffit d'en menacer les Bretons pour obtenir leur reddition sans combat!".

Or, cette puissance vasconne devait également et manifestement, sinon tout ceci devient incompréhensible, exister au début de notre ère, ce qui plaiderait en faveur d'une ancienne "amitié romano-vasconne". Si les Vascons ne posèrent pas de problème aux Romains, comme ce fut le cas des Lusitaniens, des Callaïques, des Cantabres et des Asturiens, ce n'est pas parce qu'ils étaient faibles ou peu dangereux mais simplement parce qu'ils étaient les alliés, sinon zélés, du moins fidèles de Rome et que celle-ci eut toujours confiance en eux et ne chercha pas, ce qui constituerait, il est vrai, un fait rarissime, à imposer par la contrainte son administration et sa langue. On aurait là l'explication de la survie de la langue basque qui, autrement, paraît inexplicable. Bien évidemment tout ceci ne peut pas être prouvé. Mais comment pourrait-on sinon expliquer cette survie? B. Oyharçabal ${ }^{108}$ formule également une hypothèse intéressante : On peut envisager cette question - écrit-il - d'un point de vue différent, en l'abordant de manière interne, à partir de la langue elle-même". Mais cela suffit-il à expliquer cette survivance? N'aurions-nous pas eu également affaire, du moins en partie, à un phénomène d'ordre politique? Si le basque a survécu, ne serait-ce pas essentiellement dû au fait que Rome l'a toléré parce qu'il s'agissait de la langue de populations amies et alliées, le territoire euskarophone s'étendant alors beaucoup plus vers l'est jusqu'aux Pyrénées centrales. En effet, les spécialistes constatent au fils des années et des découvertes qui se succèdent que la romanisation a atteint tout le Pays Basque, même les régions que I'on croyait il y a encore peu non affectées par celle-ci ont été indubitablement romanisées ${ }^{109}$. Dans ces conditions, le basque aurait dû, comme le gaulois ou les langues de la péninsule - certaines de ces dernières ayant été parlées par des peuples dont la résistance à Rome fut totale et absolument désespérée, par exemple les Cantabres --, reculer peu à peu devant le latin. La logique commande, réclame, voire exige le schéma qui suit : le basque aurait dû disparaître d'abord dans les actes de la vie publique organisée, comme cela était le cas dans tout l'empire, par l'autorité romaine. Ensuite, il aurait dû disparaître des classes aisées des villes vasconnes, qui auraient dû, comme partout ailleurs, chercher à se romaniser. Puis le phénomène aurait dû affecter les activités d'artisanat et de commerce et les agglomérations en général. Enfin, seules les zones rurales, notamment les zones isolées de montagne, auraient dû continuer à pratiquer le basque et au $V^{e}$ siècle, au plus tard, celui-ci n'aurait plus dû être qu'un vague souvenir. Or, ce n'est pas le cas.

Pourquoi tout ceci ne s'est pas produit dans un territoire entièrement romanisé, contrairement à ce qu'on croyait encore récemment, et habité, de surcroît, par des populations qui manifestement n'opposèrent pas de résistance aux Romains? La seule réponse qui tienne un tant soit peu est que les Basques conservèrent, malgrè la tutelle romaine, une certaine autonomie interne leur permettant d'organiser leur vie publique à leur guise. 
Beñat Oyharçabal rappelle aussi que certains auteurs ont avancé une autre hypothèse selon laquelle "la pauvreté du territoire où la langue s'est maintenue, son peuplement relativement faible et éclaté en diverses tribus, puis en provinces, l'absence d'une force militaire représentant une réelle menace pour l'extérieur, auraient permis que ces populations conservassent leur langue" "1:0. Mais cette hypothèse ne semble pas tenir étant donné que certains faits historiques la contredisent. Comme le rappelle Renée Goulard "11, "au Ir siècle de notre ère deux mentions intéressantes sont données par Tacite puis par Pline le Jeune. Tacite, dans un récit de l'année 69, présente les troupes auxiliaires de Vascones se portant au secours des Romains en difficulté sur le Rhin. La cavalerie romaine a été culbutée, les enseignes gisent à terre, la bataille est perdue. Les fantassins auxiliaires Vascones arrivent alors sur le dos des assaillants bataves avec tant de fougues que l'on crût à l'arrivée de l'armée complète de Mayence. Les Romains reprirent courage et l'avantage dans le combat. Les Vascones sont de redoutables guerriers qui connaissent non seulement la poliorcétique, mais savent combattre en fantassins".

On a là affaire à tout sauf à de pauvres montagnards et également, du moins si on en croit ce texte de Tacite, à l'inverse de "l'absence d'une force militaire représentant une réelle menace". Cela est également confirmé par le fait que, quelques siècles plus tard, Dagobert envoie dix corps d'armée en Wasconia. Eûton idée de pareille armée uniquement pour quelques montagnards habitués aux rapines et aux brigandages? Cela est difficile à croire. En ce qui concerne l'époque romaine, les Basques devaient, on l'a vu, traiter avec les Romains, sinon d'égal à égal, du moins entretenir avec eux de très bonnes relations en tant qu'alliés fỉdèles. C'est là, à notre avis, la raison principale de la survie du basque. Il s'agit, du moins nous semble-t-il, du modèle le plus cohérent, le plus réaliste et le plus économique, donc de la conjecture la plus vraisemblable.

Hector IGLESIAS Doctorant en Études Basques 


\section{Abréviations}

\begin{tabular}{|c|c|c|}
\hline$A S J U$ & $=$ & Anuario del Seminario de Filologia Vasca 'Julio de Urquijo' \\
\hline$B B M P$ & $=$ & Boletin de la Biblioteca 'Menéndez Pelayo' de Santander \\
\hline$B M B$ & $=$ & Bulletin du Musée Basque \\
\hline$B R A H$ & $=$ & Boletin de la Real Academia de la Historia \\
\hline BRSVAP & $=$ & Boletin de la Real Sociedad Vascongada de Amigos del Pais \\
\hline$B S S L A P$ & $=$ & Bulletin de lo Société des Sciences, Lettres et Arts de Pau \\
\hline$D E V$ & $=$ & Diccionario Etmologico Vasco \\
\hline$E A A$ & $=$ & Estudios de Arqueologia Alavesa \\
\hline FLV & $=$ & Fontes Linguae Vasconum \\
\hline$I D E A$ & $=$ & Instituto de Estudios Asturianos \\
\hline RDTP & $=$ & Revista de Dialeclologia y Tradiciones Populares. \\
\hline RDTP & $=$ & Revista de Dialectologia y Tradiciones Populares. \\
\hline RGPSO & $=$ & Revue Géographique des Pyrénées du Sud-Ouest \\
\hline RIEB & $=$ & Revue Internationale des Éudes Basques \\
\hline RIO & $=$ & Revue Internationale d'Onomastique \\
\hline$R L R$ & $=$ & Revue de Linguistique Romane \\
\hline$R V F$ & $=$ & Revisia Valenciana de Filologia \\
\hline$R L R$ & $=$ & Revue de Linguistique Romane \\
\hline SSLAER & $=$ & Société des Sciences, Lettres, Ants \& Études Régionales de Bayonne. \\
\hline
\end{tabular}




\section{Bibliographie}

AGUD, M. \& TOVAR, A., 1989-1993, "Diccionario etimológico vasco", ASUU, T. I-VII, Saint-Sébastien.

ALBERTOS FIRMAT, Mª. L., 1966, La Onomástica personal primitiva de Hispania : Tarraconense y Bética, Université de Salamanque.

ALLIĖES, J., 1998, "Michel Morvan : Les origines linguistiques du Basque", in Lapurdum III', pp. 315-317.

ALONSO AVILA, A., 1987, "Navarra y los vascones durante la época visigoda", in Primer Congreso de Historia de Navarra, 2, Pampelune, pp. 277-292.

ALTADILL, J., 1914, Geografia General del Reino de Navarra, 2 vol.

AZKUE, R.-M., 1905-1906, réed. 1984, Diccionario Vasco-español-francés, Bilbao.

BELASKO, M., 1996, Diccionario etimológico de los nombres de los pueblos, villas y ciudades de Navarra, Ed. Pamiela, Pampelune.

BOULLÓN AGRELO, A. I., 1994, Contribución ó estudio da antroponimia medieval galega (séculos VIIL$X I I I)$, thèse doctorale inédite, Université de Saint-Jacques de Compostelle, exemplaire microfilmé.

BÚA, C., 1997, "Dialectos indoeuropeos na franxa occidental hispánica", in Galicia fai dous mil anos. O feito diferencial galego. I. Historia, G. Menaut-Pereira, coord., Saint-Jacques de Compostelle, Ed. Musée du Peuple Galicien, vol. 1, pp. 5 1-100.

CABEZA QUILES, F., 1992, Topónimos de Galicia : a súa orixe e o seu significado, Ed. Montes e fontes, Xerais.

CARBOEIRO, cart., LUCAS ÁLVAREZ, M., 1958, "La collección diplonática del Monasterio de San Lorenzo de Carboeiro", Compostellum II, 4, 1957, pp. 549-573; III, 2, I958, pp. 228-308; III, 4, pp. 549-638. Contient 90 documents de 788 à 1500.

CARO BAROJA, J., 1988, [1942, 1943], "Observaciones sobre la hipótesis del vasco-iberismo considerada del punto de vista histórico", Boletin Emerita, T. X, $2^{\circ}$, pp. 236-286, 1942, T XI, 1, pp. 1-59, 1943. et in Sobre la lengua vasca, 1988, Estudios Vascos, T. IX, Ed. Txertoa, $2^{*}$ éd, Saint-Sébastien.

CARO BAROJA, J., 1990, [1945], réed. Ed. Txertoa, Saint-Sébastien, Materiales para una historia de la lengua vasca en su relación con la latina. Estudios Vascos, XIX, Université de Salamanque.

CARO BAROJA, J., 1984, [1958], "Los estudios geográfico-históricos sobre el país vasco y la dialectologia". RDTP XIV, 1958, pp. 425-440 et in Sobre la religión antigua y el calendario del pueblo vasco, 1984, Estudios Vascos, T. I., Ed. Txertoa, Saint-Sébastien.

CARO BAROJA, J., 1972, Etnografia Mistórica de Navarra, Caja de Ahorros de Navarra, Pampelune.

CARO BAROJA, J., 1977, Los pueblos del norte de la Peninsula lbérica, 2`éd. 1976 (2 vol.), Madrid, $3^{*}$ éd. 1977. Txertoa, Saint-Sébastien.

CARO BAROJA, J., 1985, Los Vascones y sus vecinos, Estudios Vascos, T. XIII, Txertoa, Saint-Sébastien.

CARO BAROJA, J., 1988, Sobre el mundo ibérico-pinenaico : datos, nuevas ideas sobre el lberismo, Estudios Vascos, XVIII, Ed. Txertoa, Saint-Sébastien.

CHERPILLOD, A., 1986, Dictionnaire étymologique des noms géographiques, Ed. Masson, Paris.

COROMINES, J. \& PASCUAL, J. A., 1980, Diccionario crítico etimológico castellano e hispánico, 5 vol. Gredos.

COROMINES, J., 1965, [1960], "La toponymie hispanique préromane et la survivance du basque jusqu'au bas moyen âge. Phénomènes de bilinguisme dans les Pyrénées Centrales", Actes et Mémoires du IV Congrès International de Sciences Onomastiques, München, pp. 105-146. Nous utilisons la nouvelle version revue et corrigée publiée ultérieurement in. Estudis de Toponimia Catalana, T. I, Barcelona, 1965, "La survivance du basque jusqu'au bas moyen âge... ", pp. 93-15I.

COROMINES, J., 1972a, "De toponimia vasca y vasco-románica en los Bajos-Pirineos", FLV, n 12, Pampelune, pp. 299-319. 
COROMINES, J., 1972b, Tópica Hespérica. Estudios sobre los antiguos dialectos, el substrato y la toponimia romances, Madrid.

COROMINES, J, 1973, "Du nouveau sur Ia toponymie occitane", Beiträge zur Namensforschung, 8, Heidelberg, pp. 193-308.

COROMINES, J, I 974, "Elementos prelatinos en las lenguas romances hispánicas", Actas del I Coloquio sobre lenguas y culturas prerromanas de la Peninsula Ibérica, Salamanque.

DAUZAT, A.et ROSTAING, Ch., 1989, Dictionnaire étymologique des noms de lieux en France, Paris, nouvelle édition.

DAVID, P., 1947, Études historiques sur la Galice et le Portugal, du VI' au XII' siècle, Paris.

DE HOZ, J., 1997, "Lingua e etnicidade na Galicia antiga", in Galicia fai dous mil anos. O feito diferencial galego. I. Historia, G. Menaut-Pereira, coord., Saint-Jacques de Compostelle, Ed. Musée du Peuple Galicien, vol. 1, pp. 101-142.

DE LA PEÑA SANTOS, A., 1997, "Os pobos castrexos antes da conquista romana", in Galicia fai dous mil anos. O feito diferencial galego. I. Historia, G. Menaut-Pereira, coord., Saint-Jacques de Compostelle, Ed. Musée du Peuple Galicien, vol. 1, pp. 143-192.

DÍEZ MELCÓN, G., 1957, Apellidos castellano-leoneses (siglos IX-XIII. ambos inclusive), Université de Grenade.

DION CASSIUS, 1960, [édité par Ph. Boissevain, Berlin, 1895-1931, réimpr. 1955]; édité par E. W. Cary, Londres.

ENCYCLOPADIA BRITANNICA, 1929-1964, 23 vol., Ed. Université de Chicago

ENTWISTLE, W.-J., 1936, The Spanish Language, together with Portuguese, Catalan and Basque, Londres, Faber and Faber.

ETCHETO, H., 1997, "Le Pays Basque Sud au temps de la conquête romaine : Vascons et Romains. 'Lamitié romano-vasconne"', in Ekaina, Revue d'Etudes Basques, n 63, pp. 163-188.

EUSKALTZAINDIA, , 1990, Nafarroako herri izendegia / Nomenclátor euskérico de Navarra. Pampelune.

EUSKALTZAINDIA, 1991, Onomasticon Vasconiae 4. Actas de las / jornadas d' onomástica. toponimia. Vitoria-Gasteiz, abril 1986 /I onomastika jardunaldien agiriak Tojonimia, Gasteiz, 1986ko apirila. Ed. Euskaltzaindia.

FERNÁNDEZ REI, F., 1991, Dialectoxia da lingua galega, Ed. Xerais.

FOUCHE, P., 1939, "A propos de l'aragonais 'Ibón'", in Melanges Martinenche, Paris.

GAMilLSCHEG, E., 1950, Romanen und Basken, Wiesbaden, Franz Steiner.

GARCIA ARIAS, X. LL., 1977, Pueblos asturianos : el porqué de sus nombres, Ed. Ayalga, Collección Popular Asturiana, Gijón.

GAVEL, H., 1921, "Eléments de phonétique basque", RIEB, XII, an 15. pp. 1-542

GAVEL, H., 1931, "Du nom de Bayonne et de quelques autres : noms de lieux aquitains ou espagnols", SSLAER, $\mathrm{n}^{\circ} 7$.pp. $37-47$

GAVEL, H., 1936, "Remarques sur les substrats ibériques, réels ou supposés dans la phonétique du gascon et de l'espagnol", RLR, T. XII, $\mathrm{n}^{\circ}$ 45-46.

GGRG = Geografia General del Reino de Galicia, 1980, 13 vol, sous la direction de F. Carreras y Candi, Ediciones Gallegas, Editorial La Gran Enciclopedia Vasca, La Corogne-Bilbao.

GIFFORD, J., 1955, “Topónimos gallegos y topónimos navarros", BRSVAP, XI, pp. 227-231

GÓMEZ-MORENO, M., 1925, "Sobre los iberos y su lengua", Homenaje ofrecido a Menéndez Pidal, III, pp. $225-240$.

GONZÁLEZ ECHEGARAY, J., 1997, Las Cänabras, 4 ẻd. revue et actualisée, Ed. Estudios, Santander. 
GORROCHATEGUI CHURRUCA, J., 1984, Estudio sobre la onomástica indigena de Aquitania, Ed. Université du Pays Basque (UPV-EHU), Bilbao.

GORROCHATEGUI CHURRUCA, I., 1995, "Basque and its neighbors in Antiquity", in Towards a History of the Basque Language, J. Benjamins, Amsterdam/Philadelphie, pp. 31-64.

GORROCHATEGUI CHURRUCA, J., 1997, "Gallaecia e as linguas prerromanas da Peninsula Ibérica”, in Galicia fai dous mil anos. O feito diferencial galego. I. Historia, G. Menaut-Pereira, coord., SaintJacques de Compostelle, Ed. Musée du Peuple Galicien, vol. 1, pp. 15-49.

GOULARD, R., 1997, "Wascones in plana descendunt... Civitas Lapurdum... ", in Lapurdum II, pp. 257. 282.

GOYHENECHE, E., 1966, Onomastique du Nord du Pays Basque au Moyen Age. XI-XVe siècles, thèse de doctorat dactylographiée, Bordeaux.

GROSCLAUDE, M., 1991. Dictionnaire toponymique des communes du Béarn. Pau.

HUBSCHMID, J., 1960, "Lenguas prerromanas de la Peninsula f́bérica. A.- Lenguas no indoeuropeas. 2.Testimonios románicos", in M. Alvar et alii, Enciclopedia Lingü̈stica Hispanica (ELH), Madrid, vol. 1, pp. 27-66; pp. 127-149; pp. 447-493.

HUMBOLDT, W. v., 1921, Prüfung der Untersuchungen über die Urbewohner Hispaniens vermittelst der Vaskischen Surache, Imp. F. Dümmler, Berlin, 192 pages. Traduction espagnole de T. Aranzadi : "Examen de las investigaciones sobre los aborigenes de España mediante la lengua: vasca, traducción directa del alemán (2* edición) por Telesforo de Aranzadi", RIEE, 1934, pp. 475-520 et RIEB, 1935, pp. 44-92; pp. 499-552. Version française: Recherches sur les habitants primilifs de l'Espagne à l'aide de la langue basque, Traduction de M. A. Marrast, Paris, impr. ToInon, 1866.

HYDACE, Chronique, 1974, édité par Alain Tranoy, 'Sources Chrétiennes', n' 218-219, Paris.

IGLESIAS, H, 1998a, "Le toponyme Biarritz", FLV, n 78, pp. 281-288.

IGLESIAS, H., 1998b, "Sur quelques similitudes toponymiques galaïco-basques et le problème que posent certaines d'entre elles", Lapurdum /ll, 1-29.

IGN, Insiatuto Geográfico Nacional. Plusieurs cartes 1:25.000 et I : 50.000 concernant la Galice et les Asturies ainsi que Atlas routier ef touristique Espagne \& Portugal, 1999, échelle I : 400000, Ed. Michelin.

IRIGARAY, A. \& MICHELENA, L., 1955, "Nombres vascos de persona”, BRSVAP, XI, pp. 405-425.

IRIGOIEN, A., 1985, "Sobre los topónimos Oca y su entorno", Symbolae Ludovico Mitxelena septuagenario oblatae, Université du Pays Basque (UPV-EHU), Instituto de Ciencias de la Antigüedad, Vitoria, pp. $6007-1017$.

IRIGOYEN [IRIGOIEN], A., 1986, En torno a la toponimia vasca y circumpirenaica, Deusta.

IRIGOIEN, A. 1987, "Leku-izenen euskarazko formak Nafarroan". De re philologica linguae uasconicae, Bilbao, pp. 263-264.

IRIGOIEN, A., 1992a, "Lea-Artibai alderdia", De re philologica linguae uasconicae IV, Bilbao, pp. 357 358.

IRIGOIEN, A., 1992b, "Miscellanea toponymica et anthroponymica (III-IV)", De re philologica linguae uasconicae $I V$, Bilbao, pp. 213-224: 225-230.

JAUPART, F., I981, Le nom de Bayanne, les lietx. les persannes. T. I ei II, Bayonne.

JUBIA [mod. XUBIA], cart., 1935, MONTERO DÍAZ, S., La collección diplomática de San Martin de Jubia [Xubia, Ferrol], Saint-Jacques de Compostelle. Contient 130 documents allant de 977 à Il 199.

JUNGEMANN, F., 1955, La teoria del sustrato y los dialectos hispano-romances y gascones, Madrid.

LAFON, R., 1958, "Noms de lieux d'aspect basque en Andalousie", tiré à part des Actes et Mémoires dus 5 Congrès International de Sciences onomastiques, vol, II, Salamanque, pp. 3-12.

LAFON, R, 1999a, [1973], "La langue basque", BMB, 1973, pp. 57-120 et in Vasconiana, in Iker-ll, 1999, pp. 3-55. 
LAFON, R., 1999b, [1934], "Sur quelques cas de dilation vocalique régressive", Iker-11, Vasconiana et in RIEB, XXV, 1934, pp. 666-671.

LAMBERT, P.-Y., 1994, La langue gauloise, Ed. Errance, Paris.

LANGANEY, A., CLOTTES, J., GUILAINE, J. \& SIMONNET, D., I998, La plus belle histoire du monde, Ed. Seuil, Paris.

LARREA, J.-J., 1998, La Navarre du $W^{*}$ au XII siècle : peuplement et société. Ed. De Boeck Université, Paris, Bruxelles.

LECUONA, M., 1960, "El euskera en Navarra a fines del siglo XVI", Geografia historica de la lengza vasca (siglos XVl al $X(X)$, Collección Auñamendi.

LÓPEZ de GUEREÑU GALARRAGA, G., 1989, Toponimia alavesa seguido de mortuorios o despoblados y preblos alaveses, in Onomasticon Vasconiae 5, Euskaltzaindia.

LORENZANA, cart., RODRÍGUEZ GONZÁLEZ, A. \& REY CAIÑA, J.-A.. I992, Tumbo de Lorenzana, Saint-Jacques de Compostelle. Contient 222 documents allant de 969 a 1266 à partir d'un manuscrit ancien dép̧osé aux Archives Historiques Nationales de Madrid.

LOSIQUE, S., 1971, Dicionnaire étymologique des noms de pays er de peuples, Ed. K.lincksieck, Paris.

LOUANDRE, CHi., 1931, Commentaires de Jules César. Guerre des Gaules, Traduction nouvelle avec le texte, des notes et un index, Ed. E. Fasquelle, Paris.

LUCHAIRE, A., 1874-1875, "Du mot basque $I R I$ et de son emploi dans la composition des noms de lieux de l'Espagne et de l'Aquitaine antique ", BSSLAP, pp. 18-27.

MADOZ, P., 1845-1850, Diccionario geográfico-estadistico-histónico de España y sus posesiones de Ultramar, 16 vol, Madrid

MARIÑO PAZ, R., 1998, Historia da lingua galega, Ed. Sotelo Blanco, Saint-Jacques de Compostelle.

MARTINEZ BARBEITO, C., 197 I, Galicia, Ed. Destino, Barcelone, 3éd.

MARTINO, E., 1995, Roma contra cántabros y astures. Nueva lectura de las fuentes, Collección Brevarios de la Calle del Pez, Ed. Diputación Provincial de León.

MELA, P., 1935, De chorographia, édité par K. Frick, Leipzig.

MELA, P., 1875, Euvres complètes, avec la traduction en français, publiées sous la direction de M. Nisard de l'Académie Française, Inspecteur Général de l'Enseignement Supérieur, Ed. Firmin-Didot, Paris.

MENÉNDEZ PIDAL, R., 1968, Toponimia Prerrománica Hispánica, Gredos, Madrid.

MEZQUiRIZ, M. A., 1986, "Pavimientos decorados hallados en Andelos", in Trabajo de Arquelogia Navarra, 5, pp. 237-249.

MICHELENA, L., 1964, Sobre el pasado de la lengua vasca, Collección Auñamendi, Saint-Sébastien.

MICHELENA, L., 1981, "Lengua comun y dialectos vascos", ASJU, XV, pp. 291-313 et in Palabras y Texios, 1987, pp. 35-55.

MICHELENA. L., 1982, "Sobre la historia de la lengua vasca", ASJU, XVI, pp. 143-156 et in Palabras y Textos, 1987, pp. 9-21.

MICHELENA, L., 1989, Apellidos Vascos, $4^{c}$ éd., Txertoa, Saint-Sébastien.

MICHELENA, L., 1990, [1964], Textos arcaicos vascos, ASJU, Saint-Sébastien; I" èd. Minotauro, Madrid, 1964.

MORA.EJO LASSO, A., 1944, “Observaciones sobre el estudio de la toponimia gallega", Cuadernos de Estudios Gallegos, I, pp. 59-72.

MORALEJO LASSO, A., 1977, Toponimia gallega y leonesa, Ed. Pico Sacro, Saint-Jacques de Compostelle. 
MORALEJO LASSO, A., 1978, "Ojeada a los topónimos hispánicos y especialmente a los gallegos de origen prelatino de J. Corominas", Verba 5, Anuario galego de filoloxia, pp. 13-24, Université de SainttJacques de Compostelle.

MORLET, M.-Th., 1972, Les noms de personne sur le territoire de l'ancienne Gaule du VF au XII siècle. I.- Les noms issus du germanique continental et les créations gallo-germaniques. II. Les noms latins ou transmis par le latin, Paris, CNRS.

MORVAN, M., 1995, "A. propos d'une thèse de doctorat d'études basques : Les origines linguistiques du basque : l'ouralo-altaīque", $B M B, \mathrm{n}^{\circ} 139$, pp. $33-47$.

MORVAN, M., 1996, Les origines linguistiques de basque : I'ouralo-altaïque, thèse de doctorat, Université de Bordeaux III, publiée sous le titre Les origines linguisiques du basque, Presses Universitaires. Bordeaux

NEGRE, E., 1963, Les noms de lieux en France, Collection Armand Colin, Paris.

OLANO SILVA, V., 1945, 1949, 1954, "Toponimia gallega", RDTP, I., 1945, pp. 653-666; V., 1949, pp. 626-662; X., pp. 190-226, 1954.

ORPUSTAN, J.-B., 1990, Toponymie basque, Presses Universitaire de Bordeaux.

ORPUSTAN, J.-B., 1999, La langue basque an Moyen Áge, Izpegi.

OSEIRA, cart., ROMÁNI MARTINEZ, M., 1989, Colección diplomática do mosteiro cistercience de Santa Maria de Oseira (Ourense), Conselleria da Cultura, Saint-Jacques de Compostelle. Documents allant de 1025 à 1310.

OYHARCABAL, B., 1989, "Variété dialectale et unification littéraire", in Euskal Herriak / Pays Basques, $\Upsilon$. II, Les cahiers de l'IFOREP, $n^{\circ} 57$, Paris, pp. 18-22.

OYHARÇABAL, B., 1998a, "A propos de la langue basque", in La question basque, Denis Laborde, coord., Ed. LHarmattan, Paris, pp 41-55.

OYHARÇABAL, B., 1998b, "R. L. Trask. The history of Basque", in Lapurdum III, pp. 317-333.

PEREIRA-MENAUT, G., 1997, "Un pobo c unha natio moi particulares", in Galicia fai dous mil anos. O feito diferencial galego. I. Historia, G. Menaut-Pereira, coord., Saint-Jacques de Compostelle, Ed. Musée du Peuple Galicien, vol. 1, pp. 237-249.

PIEL, J. -M., 1945, Os nomes germánicos na toponimia portugesa, I. Adaes-Novegildo. Lisbonne, 1937. II. Oldmes-Zendo. Lisbonne.

PIEL, I. -M., 1948, "Nomes de posssessores latino-cristãos na toponimia asturo-galego-portuguesa", Biblos, 23, pp. 143-202.

PLINE l'ANCIEN, 1850-1851, Histoire naturelle de Pline, avec la traduction en français, par M. Emile Littrê, Paris, 2 vot.

PLINI SECUNDI, C., 1906, Naturalis Historiae, vol. I, Libri I-VI, post Lvdovici lani obitvm, recognovit et scriptvrae discrepantia adiecta edidit Carolvs Mayhoff, MCMVI, Lipsiae in aedibvs B. G. Tevbneri. Edition de Carl Mayhoff, qui a repris et renouvelé l'oeuvre de Jan après la mort de celui-ci, Leipzig, Teubner; version latine seule et pas d' index.

PLINE L'ANCIEN, 1950, Histoire Naturelle, Livre I, texte établi, traduit et commenté par Jean Beaujeu, introduction d'Alfred Ernout, Ed. Les Belles Lettres, Paris.

PLINE L'ANCIEN, 1998, Histoire Naturelle, Livre III, texte établi, traduit et commenté par Huberi Zehnacker, Ed. Les Belles Lettres, Paris.

PTOLÉMÉE, C., 1883, T. I, 1901, T. II, Klaudiou Ptolemaiou Geógraphikê uphêgêsis Claudii Piolemaei Geographia. E codicibvs recognovit, prolegomenis, annotatione, indicibvs, tabvlis instrvxit Carolvs Müllervs. Volvminis primi pars prima. Parisiis, A. Firmin-Didot.

PTOLÉMÉE, 1932, Géographie, édité par E. L. Stevenson, Geography of Claudius Ptolemy, New York (traduction seule).

RAVIER, X., 1963, "Le suffixe toponymique pyrénéen «-un». Le problèmẹ de ses relations avec d'autres suffixes à caractéristique nasale de l'Ibéro-Aquitain", Via Domitia, XII, fasc. 5, pp. 57-86. 
RAYMOND, P., 1863, Dictionnaire topographique des Basses-Pyrénées, Paris.

Registres Français. Délibérations du Corps de Ville, 1900-1906, T. I (1565-1580) et T. II (1580-1600), Ed. Lamaignère, Bayonne.

ROCAS, cart., DURO PEÑA, E., 1972, El monasterio de San Pedro de Rocas y su collección documental, instituto de Estudios Orensanos 'Padre Feijoo', Orense. Contient des documents allant de 1007 à 1472.

ROHLFS, G., 1952, "Sur une couche pré-romane dans la toponymie de Gas cogne et de l'Espagne du nord", $R F E, 26$, pp. $209-256$.

ROHLFS, G., 1955, [1956], "Una forma no investigada en la toponimia del sur de Francia y de la España septentrional (el sufijo -és, -iés)", traduit đu français par $J$. M. Enguita, Archivo de Filologia Aragonesa, $\mathrm{XL}$, in I Congrès Interntional de Langue et Littérature du Midi de la France, 7 au 11 septembre 1955, publié ultérieurement in Studien zur romaschen Namenkunde, Munich, 1956, pp. 114-126.

ROHLFS, G., 1970, Le Gascon. Études de philologie pyrénéenne (avec 3 cartes), 2 édition, entièrement refondue, Tübingen-Pau.

SAINT-JOUAN, R., 1966, Le nom de famille en Béarn et ses origines suivi du Dictionnaire anthroponymique du Béarn pour l'an 1385, t. I et II, réed. Librairie du Palais, 1992.

SALABERRI, P., 1994, Eslaba aldeko euskararen azterketa toponimiaren bidez. Onomasticon Vasconiae I/, Euskaltzaindia, Bilbao.

SAMOS, cant., LUCAS ÁLVAREZ, M., 1986, El tumbo de San Juliản de Samos (siglos VIIl-XII), Estudio introductorio. Edición diplomática. Apéndices e indices. Publicacións da Caixa Galicia, Saint-Jacques de Compostelle. Contient 249 documents allant de 785 à 1200.

SAN MARTÍN, J., 1991, "Introducción a la toponomástica guipuzcoana / Gipuzkoar toponomastikurako sarrera", in EUSKALTZAINDIA, Onomasticon Vasconiae 4. Acras de las I jornadas de onemástica. toponimia, Vitoria-Gasteiz, abril 1986 / I onomastika jardunaldien aririak. Toponimia. (rustaiz, 1986ko apirila, Ed. Euskaltzaindia, pp. 249-278.

SÁNCHEZ-ALBORNOZ, C, 1983, El Reino de Asturias, Ed. IDEA, Ovicdo.

SANTAMARINA, A., 1991, "Problemas para la restauración de topónimos gallegos", in EUSKALTZAINDIA, Onomasticon Vasconiae 4. Actas de las I jomadas de onomästica, toponimia, VitoriaGasteiz, abril 1986 / I onomastika jardunaldien aginak. Toponimia, Gasteiz, $1986 k 0$ apirila, Ed. Euskalizaindia, pp. 237-246.

SCHUCHARDT, H., 1907, "Iberische Deklination”, Sizzungsberichte der Wiener Akademie, 157 (II). pp. $1-90$.

SCHULTEN, A., 1927, "Las referencias sobre los Vascones hasta el año 800 después de J. C.", RIEB, XVIII, pp. 225-240.

SCHULTEN, A., 1943, Los cambabros y astures y su guerra con Roma, Madrid.

SOBRADO, cart., LOSCERTALES de GARCIA VALDEAVELLANO, M., 1976, Tumbos del monasterio de Sobrado de los Monjes, 2 vol., Dirección General del Patrimonio Artistico y Cultural / Archivo Histórico Nacional, Madrid. Contient 541 documents allant de 787 à 1252.

STRABON, 1966, Géograpłse, T. II, Liv. III-IV, texte établi et traduit par François Lasserre, Collection des Universités de France, Paris.

SUẢREZ, J. C., 1992, Toponimia lenense : origen de algunos nombres en tomo al Valle del Huerna, IDEA, Oviedo.

TRANOY, A., 1981, La Galice romaine. Recherches dans le nord-ouest de la péninsule ibérique dans l'Antiquité, ouvrage publié avec le concours du Centre National de la Recherche Scientifique (Paris), de la Casa Velázquez (Madrid) et de l'Institut d'Etudes ibériques et ibéro-américaines (Bordeaux). Publications du Centre Pierre Paris (ERA 22), Paris.

UNTERMANN, J., 1992, "Aportaciones al estudio de las lenguas prerromanas del noroeste de la Península Ibérica", in Galicia : da romanidade á xermanización. Problemas históricos e culturais, Actas do encontro cientifico en homenaxe a Fermin Bouza Brey (1901-1973), pp. 367-397. 


\section{Index alphabétique des noms de lieux et de peuples cités}

Les formes médiévales et antiques apparaissent en italique; mont. signifie montagne, riv. signifie rivière, fl. signifie fleuve, patr. signifie patronyme, top. signifie toponyme (il s'agit presque toujours de noms de villages).

Agueldo (mont., Asturies) § 32

Aldai (top. Biscaye) $\$ 31$

Aldai (top. Galice) $\$ 31$

Aldana (top. Biscaye) $\$ 31$

Alday (top. Alava) $\$ 31$

Alderiz, Alderitz, Aldériz (top. Galice et Navarre) $\S 50$

Andelo (top. Galice et cité vasconne de

l'Antiquité) $\$ 32$

Anderiz (top. Galice) $\$ 50$

Aralde (top. Galice et Navarre) $\$ 33$

Arán (top. Galice) \$ 34

Arana (mont. Andalousie) $\$ 40, n .71$

Aranga (top. Galice) $\$ 35$

Arantza (top. Navarre) $\$ 36$

Aranza (top. Galice) $\$ 36$

Arca (top. Galice) $\S 31$

Archaa (top. Galice) \$31

Archay (top. Galice) $\$ 31$

Arcogaña (mont. Galice) $\S 40$, n. 72

Arga, Argá (mont. Portugal, top. Galice, riv.

Navarre) $\$ 37$

Argán (top. Galice) $\$ 37$

Argaxá, Argaxo, l'Arguexu, La Argarama (top. el moni. Asturies) $\$ 37$

Argonde (top. Portugal) $§ 38$

Argonte (top. Galice et Portugal) $\S 38$

Argote (top. Galice et Alava) $\$ 38$

Argote, Argot (top. Alava) $\$ 38$

Arroni (peuple galaïque de I'Antiquité) \$ 39

Arronidaeci (peuple de l'Antiquité, Asturies. $\$ 49$, n. 88

Arros, Arrós (top. Galice, Basse-Navarre et (atalogne) $\$ 39$

Arteaga (mont. Galice) $\$ 40$

Arteaga (top. Biscaye et Navarre) $\$ 40$

Artedo (top. Asturies) $\$ 40$

Arteixiña (top. Galice) $\$ 40$

Arteixo (top. Galice) $\$ 40$

Artés (top. Catalogne) $\$ 40$

Artes (top. Galice) $\$ 40$

Arthez-d'Armagnac (top, Landes) $\$ 40$

Aspai (top. Galice) $\S 41$
Aspe (top. Elche, Espagne) $\$ 4 !$

Astariz (top. Galice) $§ 50$

Azanza, Azansa (top. Galice, Navarre et Labourd) $\$ 42$

Baiona (top. Galice et Labourd) $\$ 43$

Baldariz (top. Galice) $\$ 50$

Baralde (top. Portugal) $\$ 33$

Biriato (top. Labourd), n. 11

Biriatou (top. Labourd), n. 1 I

Biriatu (top. Labourd), n. II

Bizcaia (top. Galice) \$ 32

Bizcaios, Os (top. Galice) $\$ 32$

Bizkaia (top. Biscaye) $\$ 32$

CALAICIA (divinité galaïque) $\$ 5$

Cale (cité antique, mod. Porto) $\$ 5$

Calla-aici, $-u s \$ 4$.

Cappadocia $\$ 2$

Carrís, Os Carrís, Los Carrís (top. Galice) $\S 40, n$. 72

Carritz (top. Biarritz) $\S 40$, n. 72

Celtes $\$ 2$

Celici (peuple de l'Antiquité) \$44

Cova de les Llenes $\$ 17$

Degaña, Egaña (top. Asturies et Alava) $\$ 46$ Egaña, Degaña (top. Alava e ê Asturies) \$ 46

Egi, Varri (peuple galaïque de I'Antiquité) \$ 22. 23

Egivarri (peuple galaïque de l'Antiquité) $\$ 22,23$, 24

Ego (riv., Guipuscoa) $\$ 20$

egoua-v[arri] \$22, 23

Egovarri (peuple galäque de l'Antiquité) $\$ 22$,

$23,24,25$

Egovarros (peuple galaīque de l'Antiquité) $\$ 22$, 23

Eguibarr (top. Guipuscoa), n. 57

Eguiberri (patr. Labourd), n. 57

Enđériz (top. Navarre) $\$ 50$

Enériz (top. Navarre) $\$ 50$

Eo (fl. Galice-Asturies) $§ 21,25$

Eoû $\$ 19$

Esmoriz (top. Galice) $\$ 50$

Eube \$ 21, 24

Eunio \$ 21 
Euve $\$ 21,24,25$

Eygun (top. Béarn) $\$ 47$

E Eve $\$ 21$

Fonte Euve $\$ 21$

Fonteu $\$ 21$

Galatae (peuple de l'Antiquité) $\$ 2$

Galatai (peuple de l'Antiquité) $\$ 2$

Galati (peuple de l'Antiquité) $\$ 2$

Galatia \$ 2

Galicia $\$ 4$

Galicia, Galicie, Regnum Galiciae, Galicja, Galitsia, Galizien, Halicz (région d'Ukraine et de Pologne) $\$ 1$

Gallaeci (peuple de l'Antiquité, mod. Galiciens) $\$ 2$

\section{Gallaecia $\$ 4$}

Galli (peuple de l'Antiquité, Gaulois) $\$ 2$

Gallia $\$ 3$

Gaule $\$ 3$

Gigurri (peuple de l'Antiquité, Asturies) $\$ 49, \mathrm{n}$. 88

Groiri (nom basque) $\$ 50$

Goiriz (top. Galice) $\S 50$

Gueldo (mont., Galice) § 32

Héou (lac des Pyrénées) \$ 19

i-she-phannim (mod. Espagne), n. 9

Ibias, Ibia, ibia (top. Galice et Asturies) \$ 46

Igal, Igari, l'Igal (top. Navarre et Tarn) $\$ 47$

Igon (top. Béarn) $\$ 47$

Igón (top. Galice) $\$ 47$

Igon (top. Tarn) $\$ 47$

Igueldo (top. Guipuscoa) $\$ 32$

Ioû (lac des Pyrénées) $\$ 19$

Kalla-aiko- $\$ 4$

Kallaikoi \& 2

Keltoi \$ 2, 3

Lácara (top. Estrémadure) $\$ 48$

Láncara (top. Galice) $\S 48$

Landalde (top. Anglet) $\$ 49$

Landalle (top. Anglet) $§ 49$

Lángara (top. Galice et Alava) $§ 48$

Lea (riv, Biscaye) $\$ 10$

Lea (riv, Galice) $\$ 10$

Lea (top. Galice) $\$ 10$

Ledoño (top. Galice) $\$ 40$

Leia (riv., Biscaye) \& 13

Lena (fl., Sibérie) \& 14, 15, 17

Lena (riv., Asturies) $\$ 10$
Lena (top. pyrénéen) $\$ 17$

Lena, Pola de (top. Asturies) $§ 10$

Lendoño (top. Biscaye) $\S 40$, n. 71

Lerin (top. Navarre et mont. Galice) $\$ 40, n .72$

Lia (top. pyrénéen) $\$ 17$

Liai, Liei (riv., Biscaye) $\$ 13$

Liena (top. pyrénćen) $\$ 17$

Llena (top. Asturies) $\$ 10$

Londoño (top. Galice) $\$ 40$, n. 71

Lusitania \$ 8

Maitiena. (riv. Andalousie) $\$ 40, n .71$

Navarri \& 25

Oderitz (top. Navarre) $\$ 50$

Oo (top. et lac des Pyrénées) \$ 19

Orduña (top. Biscaye et mont. Andalousie) $\$ 40$, ก. 7 !

Oriz, Oritz, Oriz (top. Portugat, Galice, Navarre) $\$ 50$

Orro (top. Galice) $\S 40$

Osteritz, Ostériz (top. Navarre) $\$ 50$

Ove (fl., Galice-Asturies) $\$ 21,25$

Port de la Lleia (top. pyrénéen) $\$ 17$

Porto (top. Portugal) $\$ 5$

Portucale. Portus Cale, Portugale (top. mod. Portugal), n. 21

Riberas de Lea (top. Galice) $\S 10$

Rodeigón, San Crisióbal (top. Galice) § 47

Serra la Llena (top. pyrénéen) \& 17

Tinapu (top. Navarre), n. []

Tiribidi (mont. Galice) $\$ 40$, n. 72

Toloño (mont. Alava) $\$ 40$

Toroño (top. Galice) $\S 40$

Treviño (top., Asturies) $\$ 32$

Triapo, Triapu (top. Navarre), n. 11

Uncin (riv., Asturies) \& 18

Untxin (riv., Urrugne, Labourd) $\$ 18$

Uoû (lac des Pyrénées) $\$ 19$

Uria (top. Asturies) $\$ 49$

Uriz, Uritz, Úriz (top. Galice et Navarre) \& 5()

Urrea (top. Aragon) $\S 49$

Urria (top. Burgos, Aragon et Asturies)

Urrialdo, Urrialdu (top. Alava) $\$ 49$

Urriategui (top. basque) $\S 49$

Urriaurra (top. basque) $\$ 49$

Urricosola (top. basque) $\$ 49$

Urriellu, Urriello (mont. Asturies) $§ 49$

Urriés (top. Aragon) $\$ 49$ 
Urrós, Urros, Urro(t)z (top. Portugal, Galice, Navarre) $\$ 49$

Ustaize (top. Navarre) $\$ 50$

Ustaritz (top. Labourd) $\$ 50$

Ustariz (top. Galice) $\$ 50$

Ustarriz (top. Alava) $\$ 50$

Ustés (top. Navarre) $\S 50$

Varduli, Vardulli et Barduli, Bardili (peuples de l'Antiquité) \$ 44

Vascones (peuple de I'Antiquité) $\$ 6$
Velate, Belate (mont., Navarre) $\$ 45$ Veleiates (peuple de I'Antiquité) $\$ 45$ Vellates (peuple de l'Antiquité) $\$ 45$ Verkhoïansk (mont., Sibérie) \$ 14 Vilate, Santae Mariae de (top. Galice) $\S 45$ Villaodriz (top. Galice) $\$ 50$ Vizcaya (top. Galice) $\$ 32$ Yube (fl., Galice-Asturies) \&2l 
1. Iglesias, $1998 \mathrm{~b}$.

2. Santamarina, $1986 / 1991$, p. 246.

3. Mariño Paz, 1998 , p. 416.

4. C"est certe sorte d"étrangeté" qu'ils dégagent involontairement - c'est en fait l'énorme compacité de leurs comportements socio-culturels, la plupart du temps archaïsants, et linguistiques qui se trouve être à l'origine de cette "bizarrerie" - qui a souvent et jusqu'a une date encore récente quelque peu marginalisé, malgré eux, les Galiciens par rapport aux autres populations de la péninsule.

5. De la Peña Santos, 1997, p. 145.

6. Mariño Paz, 1998, p. 28.

7. Hubschmid, 1960, p. 149.

8. Tranoy, 1981, p. 53

9. Allincic (VIII, 330c, traduction de D. Roussel, cité par Tranoy, 1981, p. 92) cite le témoignage de l'historien grec Polybe qui avait voyagé en Espagne au côté đe Scipion en 151 av. J.-C. : "Polybe - écrit Athénée - nous parle de la Lusitanie, une partie de l'Ibérie, ou de l'Espagne [Hispanie] selon le nom que les Romains donnent aujourd'hui à ce pays". L'origine du nom de l'Espagne ou Hispania est inconnue. On pense qu'il viendrait cependant du phénicien $i$-she-phanim, "Côte des lapins" (Pline, 1998, commentaire de Zehnacker, p. 123, \$ 8). En effet, l'Ibérie était, d'aprés les auteurs antiques, un pays extrêmement abondant en lapins.

10. Humboldt, 1821, §XXXVIII.

11. Ce nom est également attesté dans une inscription trouvée en Navarre, dans le village de Gastiain (Vallée de Lana, Estella) comme le signale $\mathrm{M}^{3}$ Lourdes Albertos (1966, pp. 250-25 I). Ce nom antique rappelle curieusement, comme le signalait Luis Michelena $(1987$, p. 158, \& 8), celui de la localité labourdine appelée Biriatu, autrefois Biriato, 1552. Michelena émettait également l'hypothèse selon laquelle Biriatu et Tirapu auraient peut-être pu être apparentés d'un point de vue étymologique : il faudrait alors, écrivaitII, supposer que Biriatu serait issu de < *briatu < "priatu et que Tirapu, autrefois Triapu, 1065, Triapo, 1100, serait issu de ce *Priatu suite à une métathèse : *Priatu > Triapu. Quant à *Priatu, il aurait pu Étrc issu du lat. prinatus suite à une perte du-v-par dissimilation. L'exercice est, comme il le reconnaissaif luimême, périlleux, quoique plausible. Mais pourquoi ne pas supposer, comme au demeurant Luis Michelena semblait le suggérer lui-même dans son article, que Biriafu est issu de l'anthroponyme attesté en Navarre Virianus?

12. Tranoy, 1981, p. 53, n. 123.

13. C'est dans une localité indigène appelée Cinginnia, qui n'a toujours pas été identifiée, que Brutus obtint sa première face aux populations locales. Tite-Live raconte alors que, profitant de son succès, Brutus poursuivit sa route vers le nord à travers le territoire des Callaeci atteignant ainsi le fleuve Limaeas (actuel Lima, nord du Portugal). Les Romains croyant que c'était là le fleuve de l'oubli et que quiconque osait le traverser oubliait tout, même ses origines et son pays natal, prirent peur. Brutus, racontent dans un style quasi homérique les écrivains antiques, s'empara alors de l'enseigne que le signifier refusait de transporter sur l'autre rive et traversa le premier le fleuve afin que le reste de l'armée le suivît. Par la suite, son expédition n'alla pas au-delà du fleuve Miño ou Bainis, c'est-à-dire qu'il ne put entrer dans l'actuelle Galice car il eut à combattre un autre peuple de la Callaecia : Ies Bracari qui se battaient aux côtés de leurs femmes, ces dernières luttant jusqu à la mort et prefferant, raconte Appien, tuer leurs enfants et se donner la mort plutôt que de tomber aux mains de l'ennemi. Après cet épisode, Brutus abandonna la région et Rome ne s'intéressa plus sérieusement à ce qui constitue le territoire galicien actuel - dans lequel ses armées n'avaient pas au demeurant encore pénétré - pendant près de quatre-vingt ans, jusqu'en 60 av. J.-C., année au cours de laquelle Jules César, qui avait reçu le gouvernement de l'Hispania Ulterior, entreprit, à la tête de trois légions, une incursion dans la Galice d'aujourd hui af in d'y chercher des mines d'or et acquérir quelque gloire personnelle puisque, signale Alain Tranoy, "le voyage dans des régions dont la réputation de barbarie était bien établie suffisait à donner à celui qui l'avait réalisé un prestige nouveau. exprimé par le titre d'Imperator dont le gratifièrent ses soldats" (Tranoy, 1981, p. 131). Après quoi, il faudra attendre la fin des guerres cantabres menées par Auguste pour que la Galice soit définitivement intégrée dans l'Empire romain. Le terme Callaecia est quant à lui une invention romaine. Il s'agit d'un nom 
désignant une nouvelle structure géo-politique issue des réformes entreprises par l'empereur Auguste après la. longue et pénible conquête du Nord-Ouest. Les érudits et les chercheurs ne sont cependant pas tombés d'accord au moment de dater ces réformes, les dates proposées oscillant entre les années $15,13 \mathrm{et} 9 \mathrm{av}$. J.-C. Nul n'est capable de dire si les habitants de cette province désormais appelée par les Romains Callaecia avaient concience ou non d'exister en tant que natio, les seules certitudes étant que Rome, pour des raisons qui nous échappent en partie, considérait que les habitants de ce territoire formaient assurément sinon une nation, tout au moins une aire culturelle homogène - malgré une hétérogénéité linguistique. admise de nos jours par tous les auteurs et dont les Romains eux-mêmes semblaient avoir concience - et đ'autre part il est clair que tous les indigènes ne pouvaient se désigner eux-mêmes comme Callaeci puisque ce nom, on l'a dit, n'étail rien d'autre que celui d'un peuple attesté au cours du II siècle av. J.-C. Le premier document où on constate qu'un individu se défini comme étant un Galicien, c'est-à-dire un Callaecus apparait dans une inscription funéraire du III' siècle trouvée à Tarragone : Q. VOCONIVS RVFINVS CALL AECVS. Le doute réside dans le fait qu'on ne sait pas si on doit considérer ce nom dans son sens restreint ou dans son rôle de non de peuple éponyme.

14. Tranoy, 1981, p. 375.

15. Tranoy, 1981, p. 372, Pereira-Menaut, 1997, p. 239

16. Pereira-Menaut, 1997, p. 247. Lorsque un Espagnol va en Galice sans avoir pris la précaution de s'informer et qu'il décide de visiter les zones rumales, c'est-ä-dire la quasi totalité du territoire, il peut être surpris et dérouté par ce qu'il voit. Alors que la nomenclature des villages, en l'occurrence galiciens, qu'il a consultée lui indique, par exemple, que la localité X est une municipalité de 5000 habitants (l'équivalent grosso modo du bourg d'Hasparren), lorsqu'il arrive sur place il ne voit, à sa grande surprise, rien ou presque rien. C'est qu'en réalité les localités galiciennes sont composées d'une multitude de paroisses qui a leur tour sont elles mèmes composées d'une multitude de hameaux, le tout étant dispersé sur des kilomètres, cette đispersion étant liée, on l'a vu, à des structures socio-politiques héritées de l'Antiquité sclon, entru uutres, Pereira-Menaut. Ce système très original serait alors une survivance pré-romaine qui n'aurait pas d’équivalent dans le reste de la péninsule et qui expliquerait pourquoi on trouve plus de toponymes 1miturs dans ce pays que dans tout le reste de l'État espagnol.

17. Cherpillod 1986, p. 183.

18. Caro Baroja, 1988, p. 50

19. Entwistle, 1936, p. 38.

20.) Lambert, 1994, p. 34.

21. Lhistorique du nom de ce peuple est un peu complexe car il semble y avoir eu confusion chez les auteurs anciens entre le peuple des Callä̈ques à proprement parler, c'est-ä-dire au sens restreint, et le rôle de peuple éponyme qu'il fut amené à jouer par la suite en représentant l'ensemble đes populations établies dans les conuentus de Braga et de Lugo. C'est encore Strabon (Géogr., III, 3, 3) qui nous explique comment ce nom fut étendu à l'ensemble des populations de cette région, "les autres peuples ayant des noms trop obscurs". Pline l'Ancien le cite encore avec un sens restrictif, ce qui laisserait supposer qu'à son époque ce peuple existait encore en tant que tel. Le problème que pose ce populus en ce qui concerne sa localisation exacte n'a pas pu encore être tranché par les divers auteurs qui se sont penchés sur la question. A I'heure actuelle, le rapprochement le plus vraisemblable avec le nom des Callaïques est celui qui a été fait avec celui de l'antique nom de Porto : Cale, Portus Cale, Portucale (Hydace, V' siècle), Portugale ( $V I^{e}$ siècle). Cale était une ancienne localité indigène construite sur la rive sud du Douro. Le site n"étant pas favorable à la navigation, on construisit sur la rive nord une ville appelée Portus Cale, "le port de Cale" qui est à l'origine de l'actuel nom đu Portugal.

22. Tranoy, 1981, p. 66.

23. Tranoy, 1981, p. 66.

24. Untermann, p. 393, n. 80.

25. Agud. M. † \& Tovar, A., DEV. T. V, 1992, 303, tiré de Michelena, L., BRSVAP, 11, p. 291.

26. Caro Baroja, 1977 , p. 38 , n. 8 .

27. Tranoy, 1981, p. 94.

28. Tranoy, 1981, p. 118, Caro Baroja, 1976, p. 252, ฉ. 205. 
29. Tranoy, 1981, p. 118.

30. Sirabon, 1966, commentaire de François Lasserre, p. 50, n. 2

31. Cependant, il semblerait qu'on ne puisse pas, comme le font certains auteurs, qui ne s'embarrassent d'aucune sorte de précaution, écrire : voici quel était le mode de vie des Basques de l'Antiquité. On devrait peut-être au contraire rapporter, afin de ne pas créer de confusions inutiles, les faits tels qu'ils sont. Autrement dit : voici quel était il y a deux mille ans, d'après Strabon, le mode de vie des Lusitaniens et des Galiciens, mode de vie qui était, toujours selon Strabon, également celui des Asturiens, des Cantabres et des Vascons. Le témoignage de ce géographe grec apparait en effet dans la deuxième partie du Livre III qui est entièrement consacrée à la description détaillée de la Lusitania et de ses habitants (et par conséquent de la Callaecia pour les raisons évoquées auparavant), la première partie étant quant à elle consacrée à la Turdetania qui était un pays couvrant principalement la vallée inférieure du Guadalquivir. De nombreux ouvrages de vulgarisation, la plupart đu temps destinés principalement à l'enseignement de l'histoire du Pays Basque, attribuent en effet systématiquement aux Vascones des descriptions ne les concernant pas en réalité directement. En outre, Joaquin González Echegaray, dans l'un de ses ouvrages destiné principalement aux spécialistes et intitule Los Cántabros (1997, $4^{e}$ éd., pp. 105-109), un peuple qui habitait grosso modo, l'actuelle région de Santander, attribue, cette fois aux seuls Cantabri, la description que Strabon faisait en réalité des Lusitaniens. Or, si cela n'est pas précisé, le lecteur, qui souvent n'a pas accès au texte de Strabon, ne peut pas le savoir. Un des seuls et rares passages - au nombre de trois ou quatre en tout - de Strabon (Géogr., III, 4, 18), rappelons-le, concernant strictu sensu les Cantabres, et seulement les Cantabres, apparaît dans la troisième partie de son ouvrage consacré à l'Ibérie proprement dite. Le passage, célébrissime, est le suivant: "Chez les Cantabres, par exemple, c'est l'époux qui apporte la dot à sa femme, ce sont les filles qui héritent et qui choisissent l'épouse à laquelle destiner leurs frères. Ces coutumes relèvent d'un régime de gynécocratie qu'on ne saurait en aucune manière qualifier de policé". Ce court passage eut, entre autres, pour conséquence de déchaîner les passions en Pays Basque, encore et surtout au XX' siècle, où on l'attribua aux Basques de l'Antiquité donnant ainsi naissance à un des mythes parmi les plus prisés du nationalisme basque contemporain : le "matriarcalisme basque".

32. Iglesias, $1998 \mathrm{~b}$.

33. Garcia Arias, 1977, p. 54.

34. Coromines, 1972, pp. 163-164.

35. Coromines, 1972, p. 163, n. 7.

36. Irigoyen, 1992a, p. 357.

37. Gavel, 1921, p. $87, \$ 41$

38. Iglesias, 1998b, p. 4.

39. Irigoyen, 1992a, p. 358.

40. Allières, 1998, p. 316.

41. Allières, 1998, p. 316.

42. Encyclopædia Britannica, 1929-1964, p. 909.

43. Cherpillod, 1986, p. 267

44. Cornme le signale le généticien André Langaney (Langaney/Clottes / Guilaine, 1998, pp. 4 I-43), pour expliquer l'étonnante homogénété génétique des populations actuelles à travers toute la planète, la seule explication, d'après les recherches les plus récentes basćes, entre autres, sur des simulations réalisées sur ordinateur, est d'admettre que le nombre des populations prèhistoriques, à une époque pas trop lointaine, ait été très faible, "à la limite de l'extinction de leur population". On estime ainsì que tous les êtres humains actuels descendent d'une seule et unique population d'environ 30000 personnes - c'est-à-dire l'équivalent d'une ville comme Biarritz pour peupler l'ensemble de la planète - connus sous le nom de Homo sapiens sapiens et concentrée probablement dans certaines régions du Proche-Orient. Cette population serait apparue entre 150000 et 100000 av. J.-C. Ce son des chasseurs-cueilleurs du Paleolithique, nos ancêtres directs : d'après les théories les plus récentes, ils auraient ainsi peuplé la Chine vers 67000 av. J-C., la Nouvelle-Guinée et l'Australie vers 50000 av. J.-C., l'Afrique entre 45000 et. 35000 av. J.C., l'Amérique, une première fois sans succès vers 45000 av. J.-C. et une seconde fois vers 18000 av. J.-C. et, en ce qui nous concerne, l'Europe vers 40000 av. J.-C. Ces derniers, ceux qui s'établirent en Europe, soni appelés d'ordinaire "les homme de Cro-Magnon". Or, il est également établi par la science actuelle que ces 
populations se déplaçaient vite et beaucoup. Et il en était de même à la fin des temps paléolithiques et au début du Néolithique, c'est-à-dire grosso modo vers 10000 av. J.-C., époques au cours desquelles les mouvements de populations - ces dernières étant jusqu'à la fin du Paléolithique, rappelons-le, en nombre très faible ("N'oublions pas que le monde préhistorique est presque vide" rappelle Jean Clottes, cf. 1998, p. 85) - furent constants et très importants.

45. Langaney / Clottes / Guilaine, 1998, p. 36

46. Morvan, 1996.

47. On peut par ailleurs citer, ne serait-ce qu'à titre de curiosité, le témoignage, au début du XIX'siècle, d'un philologue appelé Christian Gottlieb von Amdt, témoignage dont Michel Morvan fait état dans sa thèse (cette dernière étant controversée malgré une critique plutôt élogieuse de Jacques Allières). Ce qu'écrit Christian von Arndt est tout à fait étonnant pour son époque, dite d'ordinairè pré-scientifique : "Mais si en attendant on veut chercher des ancêtres ou des parents collatéraux à la langue basque dans d'autres régions du monde, alors on devrait de préférence les trouver au nord-est de notre continent, parmi les dialectes des Samoyèdes et d'autres populations nomadisant dans la Sibérie nord-orientale" (Morvan, 1996, p. 35). Or, le toponyme sibérien Lena (hydronyme) se trouve justement dans cette Sibérie dite nordorientale dans une région où est de nos jours parlé le yakoute, une langue altäque du groupe türk d'après Michel Morvan.

48. Rohlfs, 1970 , pp. $53-54, \S 77$ et p. $67, \S 159$.

49. Rohlfs, 1970, p. 39, \$11.

50. Registres Français, T. II, 1900-1906, p. 39.

51. Orpustan, 1999, p. 346.

52. Morvan, 1995, p. 45.

53. Rohifs, 1970, p. 53, \$ 74.

54. San Martin, 1991, p. 270.

55. Moralejo, 1977, p. 135, n. 48.

56. Moralejo, I977, p. 135, n. 48

57. Don Ramón Menéndez Pidal (1968, pp. 247-248) signale que "una gente astur (sic) [en réalité galaüque] es señalada por Plinio, IV, 111 , la de los Egivarri [il ajoute en bas de page : "Sigo la lección corriente de Plinio. La Teubneriana, hecha por MAYHоF, pone 'Egi, Varri', con evidente error"'], en cuya denominación es dificil no ver un gentilicio tomado del nombre de la ciudad o fortaleza, idéntico al de un caserio guipuzcoano, de Azpeitia, Eguibarr, repetido en el apelilido del Labourd Eguiberri; el primer elemento es egi, que en vasco moderno significa 'cresta, sierro, pico', sin duda como 'peña' en el español antiguo con significado de 'fortaleza, castillo'; asi que Egivarri es Peña Nueva, opuesto al Peña Vieja de los Picos de Europa". Mais toute la démonstration du maître était également basée sur une leçon erronée, ce qui l'invalide. En outre, Don Ramón M. Pidal croyait également, à l'instar de Humboldt et à tort, que -varrí était le basque barri. C'est en réalité à partir d'une forme Egovarri qu'il faut tenter d'analyser ce nom des Callaïques.

58. Pline, Livre I, éd. 1950 , pp. 33-34.

59. Plini Secundi, L. IV, 1906 , p. 354.

60. Iglesias, 1998 b, p. 11, \$25.

61. García Arias, 1977, p. 98.

62. Peuple d'origine celtrque fixé à l'origine dans le Sud-Ouest de la péninsule ibérique entre le Tage; et le Guadiana et dont une partie émigra en Galice d'après Strabon (Géogr., III, 3, 4).

63. Jungemann, 1955, pp. L 19-120.

64. Irigoyen, 1986, p. 56, \$52.

65. Irigoyen, 1986, p. 56, \$ 52.

66. Irigoyen, 1986, pp. 61-62, § 60 . 
67. Orpustan, 1999, pp. 279-280.

68. Michelena, 1990 , p. $33, \$ 2.1 .7$

69. Piel, 1937, p. 44, \$114.

70. Piel, 1937, p. $35, \S \S 79,80$.

71. David, 1947, p. 42.

72. Les cartes au 1:25.000 qui sont en train de paraitre depuis une vingtaine d'années (tout le territolre galicien n'est pas encore couven) sont supervisées par une commission spéciale (Santamarina, 1986/1991, p. 246) constítuée de toponymistes galiciens et d'un linguiste de l'Université nommés par le Gouvernement de Galice. Elle supervise toutes les opérations étant donné, comme nous l'avions déjà indiqué, qu'en Galice il n'existe pas de bilinguisme galicien-espagnol. En effet, seules les formes galiciennes des toponymes ont une existence légale, les anciennes formes et graphies espagnoles des noms de lieux et de rues n'existant plus d'un point de vue légal d’après la "Loi de Normalisation Linguistique de Galice" de 1983 qui, dans son article premier, stipule que "les toponymes de Galice ont pour forme unique et officielle la forme galicienne". En juin 1983, tous les partis politiques représentés au parlement autonome de Galice, où tous les débats se font uniquement en langue galicienne, votèrent également et à l'unanimité (droite galicienne néo-franquiste incluse et à l'exception des députés du Bloque Nacional-Popular Galego I Partido Socialista Galego qui avaient été expulsés du parlement en novembre 1982 pour avoir refusé de jurer frdélité à la. Constitution espagnole) la "Loi de Normalisation Linguistique". Larticle premier de cette loi stipulait que "le galicien est la langue originelle de Galice" et surtiout que "tous les Galiciens ont le devoir de la connaitre et le droit de l'uitiser". Maís le gouvernement central de l'État espagnol fit appel de cette décision devant le Tribunal Constitutionnel du Royaume d'Espagne et le 26 juin 1986, celui-ci déclara cet article inconstitutionnel en rappelant que seule la connaissance de l'espagnol constituait un devoir et non pas celle du galicien (Mariño Paz, 1998, p. 356).

73. Moralejo, 1977, pp. 341-454. On a également le village d'Orense appelé Londoño et les hameaux biscaiens appelés Lendoño de Abajo / Beitia et Lendoño de Arriba / Goitia, localité d'Orduña, en basque Urduña, cf. également la montagne andalouse appelee Orduña, $1943 \mathrm{~m}$., situee dans la Sierra Arana, à $20 \mathrm{~km}$ au nord-est de Grenade, non loin d'une rivière appelée rio Maitena, mais ici it doit s'agir, quoique cela devrait être démontré, de noms donnés après la Reconquête, ce qui ne peut être en revanche le cas en Galice.

74. Ciions également la petite montagne appelée Arcogaña située à environ $16 \mathrm{~km}$ au de la ville de LaCorogne (IGN, 1:25.000, Abegondo, 45-IV). A $10 \mathrm{~km}$ au sud-est de cet oronyme Anegaña se trouve le village de Carris, autrefois Alfonsi de Carris, s. d. prob. XII-XII! s. (cartulaire de Sobrado, cf. le rocher de Biarritz appelé Carritz < "karr- +- -itz). Trois autres montagnes de Lugo sont aussi appelées Os Carris, autrefois en espagnol Los Carris (IGN 1:50.000, Meira, 48; 1:25.000, Friol. 72-IIL/13-12; Lugo, 72-IV/1412), une d'entre elles étant située à côté d'une autre montagne appelée Tiribidi. Non loin de ce monte de Tiribidi se trouve le monte de Lerin, cf. le village navarmis de Lerín, Lerin, 1059. Un village de La Corogne s’appelle Carrió (IGN, Betanzos, I:25.000, 45-II/5-5). Un autre lieu du même nom est attesté dans la province de Pontevedra : in territorio Dece villam et eclesiam sancti lacobi que est inter Orza et Karrio, 25-VII-872. (cartulaire de Samos, mais il s'agit peut-être d'une falsification ultérieure). A côté du mont Tiribidi, on trouve le village de Corota dont le nom rappelle étrangement le nom du célèbre chef cantabre (ou asturien on ne sait pas exactement) appelé Coroconta (González Echegaray, 1997, pp. 83, 85, 108, 123, 146). L'empereur Auguste, que les Cantabres et les Asturiens avaient rendu dépressif, était, raconte Dion Cassius (LVI, 43, 3), "tellement irrité contre un certain Corocotta, un bandit espagnol très puissant., qu'i] promit publiquement une récompense de 250000 sesterces à quiconque l'arrêterait; mais plus tard, comme Corocotta s'était présenté à lui spontanément, non seulement Augusie ne lui fit aucun mal, mais de surcroît il lui offrit la somme promise". On a toutefois du mal à croire que ce chef cantabre, une sorte de: Viriathe du Nord de l'Espagne, s'est présenté, comme l'affirme Dion Cassius, devant Auguste afin de lư réclamer la récompense promise pour sa capture et que l'empereur, magnanime, a accepté de la lui donner. D'autant plus que ce dernier était devenu dépressif - à tel point qu'il avait dû par la suite abandonner le front cantabre et rentrer à Tarragone afin d’y faire une cure - à cause, en partie, dudit Corocotta.

75. Orpustan, 1990, p. 39, $\$ 38$.

76. Jaupart, 1981, p. 17.

77. Mariño Paz, 1998, p. 71. 
78. On considère que Strabon a utilisé principalement les Histoires et l'Histoire de Pompée de Posidonius d'Apamée et que les citations d'auteurs antérieurs à 72 av. I.-C., date de l'érection du Trophée du Col de Perthus, c'est-à-dire d'auteurs tels que principalement Ephore, Eratosthène, Polybe (dont l'oeuvre intitulée l'Histoire universelle consacrée aux guerres hispaniques s'arrêtait à l'année 144 av, J.-C.), Artémidore et Asclépiade de Myrléa, ont été transmises à Strabon par Posidonius.

79. Caro Baroja, 1945, p. 216

80. Michelena, 1989, p. $80, \& 193$.

81. Lafon, 1999b, p. 81

82. Agud \& Tovar, 1992, p. 874.

83. Orpustan, 1999, p. 63.

84. Agud \& Tovar, 1992, p. 874

85. Nègre, 1963 , p. 30.

86. Moralejo, 1977, pp. 30-3 I, n. 20

87. Rohifs, 1955, p. 125.

88. Irigoyen, 1986, pp. 230-231, \$ 70.

89. Iglesias, 1998b, pp. 19-20.

90. Irigoyen, 1986, p. 232. \$ 72.

91. Caro Baroja indique également (1958, n. 30): "La impresión que se tiene a primera vista es de que la romanización de los cántabros fue mayor que la de los astures y la de que éstos conservaron más elementos del antiguo estrato 'vascoide'. Nombres como el de la tribu de los 'gigurri', el de 'Arronidaeci', c. I, 1. II, 2679 y otros personales ("Neconi', c., I, I. II, 5718, 'Andoto", etc.) nos acercan al complejo aquitano".

92. Morlet, 1972, T. [, p. 44

93. Morlet, 1972, T. I, p. 44.

94. Morlet, 1972, I. I, p. 36.

95. Boullón, 1994, p. 145.

96. Salaberri, 1994, p. 126.

97. Morlet, 1972, T. I. p. I4.

98. Irigoyen, 1986, p. $78, \$ 99$

99. Silva, 1945, pp. 653 et 661 .

100. Lafon, 1999, p. 50.

I01. Oyharçabal, 1998a, p. 44

102. Martino, 1995, pp. 42-43.

103. Orose (VI, 21, 1-11) parle en effet. de plusieurs combats dans des régions galiciennes : praetera ulteriores Gallaeciae partes quae montibus siluisque consitae Oceano terminantur; Antistius et Furnius legati magnis grauibusque bellis perdonuerunt. Nam et Medultium montem Minio flumini inminentem. in quo se magna multitudo hominum tuebatur (Martino, 1995, p. 47).

104. Schulten, 1943, pp. 171-173, Martino, 1995, p. 73

105. Etcheto, 1997, pp. 167-168

106. Oyharçabal, 1998a, pp. 44-46.

107. Goulard, 1998, p. 272.

108. Oyharçabal, 1998a, p. 45. 
109. Juan José Lariea, 1998, pp. 120 121, écrit: "Sans exception, tout ce qu'on a trouvé, et qu'on découvre de plus en plus, dans le saltus Vasconum est romain : céramiques et monaies, voies, mines, monuments commémoratifs, etc. Relativement à la Vasconie méridionale et centrale, la différence réside dans la densité des découvertes, jamais dans leur attribution culturelle. Tout simplement, la carte de Caro Baroja négligeait les données de la géographie : la plus grande partie du saltus est, dans l'Antiquité comme aujourd'hui, un désert du point de vue des habitats stables. Et dans les vallées, étroites et boisées, le relief souvent tourmentẻ, l'absence de bon terroirs agricoles et les conditions climatiques - pluviosité élevée, températures exirêmes en hiver - ont toujours empêché des activités autres que l'élevage, la sylviculture et, tout au plus, une agriculture de bas rendements. Bref, des activités et des formes d'occupation qui laissent une empreinte très légère dans un milieu peu favorable à la conservation de celle-ci. Au demeurant, la comparaison de la répartition des traces romaines avec celles des vestiges protohistoriques montre que loin d'être le vase clos que l'on a prétendu, le saltus a suivi la dynamique de la région, en ce sens que l'occupation du territoire s'est intensifiée : ouverture de nouvelle voies de communication, naissance de petites agglomérations à côtés de celles-ci, poussée de la ligne des habitats stables en amont des vallées, exploitations minières... ".

110. Oyharçabal, 1998a, p. 44

I l I. Goulard, 1998, p. 260. 